\title{
A Flight Research Overview of WSPR, a Pilot Project for Sonic Boom Community Response
}

\author{
Larry J. Cliatt II ${ }^{1}$, Edward A. Haering Jr. ${ }^{1}$, Thomas P. Jones ${ }^{2}$, Erin R. Waggoner ${ }^{1}$, Ashley K. Flattery ${ }^{3}$ \\ NASA Armstrong Flight Research Center, Edwards, California, 93523 \\ Scott L. Wiley ${ }^{4}$ \\ Jacobs Technology, Edwards, California, 93523
}

In support of the ongoing effort by the National Aeronautics and Space Administration (NASA) to bring supersonic commercial travel to the public, the NASA Armstrong Flight Research Center and the NASA Langley Research Center, in cooperation with other industry organizations, conducted a flight research experiment to identify the methods, tools, and best practices for a large-scale quiet (or "low") sonic boom community human response test. The name of the effort was Waveforms and Sonic boom Perception and Response (WSPR). Such tests will be applied to building a dataset that governing agencies such as the Federal Aviation Administration and the International Civil Aviation Organization will use to establish regulations for acceptable sound levels of overland sonic booms. The WSPR test was the first such effort that studied responses to non-traditional low sonic booms while the subject persons were in their own homes and performing daily activities. The WSPR test was a NASA collaborative effort with several industry partners, in response to a NASA Aeronautics Research Mission Directorate Research Opportunities in Aeronautics. The primary contractor was Wyle (EI Segundo, California). Other partners included Gulfstream Aerospace Corporation (Savannah, Georgia); Pennsylvania State University (University Park, Pennsylvania); Tetra Tech, Inc. (Pasadena, California); and Fidell Associates, Inc. (Woodland Hills, California).

A major objective of the effort included exposing a community to the sonic boom magnitudes and occurrences that would be expected to occur in high-air traffic regions having a network of supersonic commercial aircraft in place. Low-level sonic booms designed to simulate those produced by the next generation of commercial supersonic aircraft were generated over a small residential community. The sonic boom footprint was recorded with an autonomous wireless microphone array that spanned the entire community. Human response data were collected using multiple survey methods. The research focused on essential elements of community response testing including subject recruitment, survey methods, instrumentation systems, flight planning and operations, and data analysis methods.

This paper focuses on the NASA role in the logistics and operations of the effort, including human response subject recruitment, the operational processes involved in implementing the surveys throughout the community, instrumentation systems, logistics, flight planning, and flight operations. Findings discussed in this paper include critical lessons learned in all of the above-mentioned areas, as well as flight operations results. Analysis of the accuracy and repeatability of planning and executing the unique aircraft maneuver used to generate low sonic booms concluded that the sonic booms had overpressures within $0.15 \mathrm{lb} / \mathrm{ft}^{2}$ of the planned values for 76 percent of the attempts. Similarly, 90 percent of the attempts to generate low sonic booms within the community were successful.

\footnotetext{
${ }^{1}$ Aerospace Engineer, Research Aerodynamics \& Propulsion, MS 2228, P.O. Box 273, AIAA nonmember.

${ }^{2}$ Project Manager, Aeronautics Mission Directorate, MS 2332, P.O. Box 273, AIAA member.

${ }^{3}$ Aerospace Engineer, Operations Engineering, MS 2228, P.O. Box 273, AIAA nonmember.

${ }^{4}$ Meteorologist, Research Aerodynamics \& Propulsion, MS 2228, P.O. Box 273, AIAA nonmember.
}

1

American Institute of Aeronautics and Astronautics 


\section{Nomenclature}

\begin{tabular}{|c|c|c|}
\hline AFRC & $=$ & Armstrong Flight Research Center \\
\hline ARMD & $=$ & Aeronautics Research Mission Directorate \\
\hline $\mathrm{B} \& \mathrm{~K}$ & $=$ & Brüel and Kjaerr \\
\hline BASS & $=$ & Boom Amplitude and Shape Sensor \\
\hline BEAR & $=$ & Boom Event Analyzer Recorder \\
\hline CDNL & $=$ & C-weighted day-night average sound levels \\
\hline CFD & $=$ & computational fluid dynamics \\
\hline DATR & $=$ & Dryden Aeronautical Test Range \\
\hline DFRC & $=$ & Dryden Flight Research Center \\
\hline $\mathrm{E}$ & $=$ & east \\
\hline EAFB & $=$ & Edwards Air Force Base \\
\hline "F" & $=$ & "full" sonic booms (approximately $1.2 \mathrm{lb} / \mathrm{ft}^{2}$ ) \\
\hline FAA & $=$ & Federal Aviation Administration \\
\hline GPS & $=$ & global positioning system \\
\hline "H” & & "high" sonic booms (approximately $.53 \mathrm{lb} / \mathrm{ft}^{2}$ ) \\
\hline HP & $=$ & pressure altitude \\
\hline HUD & $=$ & heads-up display \\
\hline IHONORS & $=$ & In-HOme NOise Response System \\
\hline $\mathrm{iOS}$ & $=$ & iPhone Operating System \\
\hline "L" & & "low" sonic booms (approximately $.13 \mathrm{lb} / \mathrm{ft}^{2}$ ) \\
\hline LMR & $=$ & land mobile radio \\
\hline "M" & $=$ & "medium" sonic booms (approximately $.33 \mathrm{lb} / \mathrm{ft}^{2}$ ) \\
\hline MAC & $=$ & media access control \\
\hline $\mathrm{MC}$ & $=$ & Mission Controller \\
\hline $\mathrm{M}_{\text {inf }}$ & $=$ & true freestream Mach number \\
\hline $\mathrm{N}$ & $=$ & north \\
\hline NASA & $=$ & National Aeronautics and Space Administration \\
\hline $\mathrm{NE}$ & $=$ & northeast \\
\hline NEMA & $=$ & National Electrical Manufacturers Association \\
\hline NW & $=$ & northwest \\
\hline $\mathrm{p}_{\text {actual }}$ & $=$ & actual overpressure \\
\hline PATS & $=$ & Portable Automated Triggering System \\
\hline PLdB & $=$ & perceived decibel level \\
\hline $\mathrm{p}_{\text {pcboom }}$ & & overpressure predicted by PCBoom \\
\hline PSU & $=$ & Pennsylvania State University \\
\hline $\mathrm{p}_{\text {target }}$ & $=$ & planned, targeted overpressure \\
\hline PTT & $=$ & push-to-talk \\
\hline PXI & $=$ & PCI eXtensions for Instrumentation \\
\hline ROA & $=$ & Research Opportunities in Aeronautics \\
\hline $\mathrm{RCO}$ & $=$ & Range Control Officer \\
\hline RQIDS & $=$ & Research Quick Instrumentation Data System \\
\hline SBUDAS & $=$ & Sonic Boom Unattended Data Acquisition System \\
\hline SCAMP & $=$ & Superboom Caustic Analysis and Measurement Program \\
\hline $\mathrm{S}$ & $=$ & south \\
\hline SE & $=$ & southeast \\
\hline SNOOPI & $=$ & Supersonic Notification Of OverPressure Instrumentation \\
\hline SonicBOBS & $=$ & Sonic Booms On Big Structures \\
\hline SW & & southwest \\
\hline TCAS & & Traffic Collision Avoidance System \\
\hline TSPI & & time-speed-positional information \\
\hline USPS & $=$ & United States Postal Service \\
\hline $\mathrm{W}$ & & west \\
\hline WSPR & $=$ & Waveforms and Sonicboom Perception and Response \\
\hline$\Delta \mathrm{P}$ & & sonic boom overpressure \\
\hline
\end{tabular}




\section{Introduction}

$\mathrm{T}$ he Waveforms and Sonic boom Perception and Response (WSPR) effort aligned with the need of the aerospace industry for a test analyzing community response to sonic booms with magnitudes similar to those that may be produced by future commercial supersonic aircraft. The WSPR test was a pilot effort for an eventual large-scale test wherein communities that are naïve to sonic booms will be exposed to low-amplitude sonic booms, called "low booms." The key goal was to test and demonstrate the applicability and effectiveness of techniques to gather data relating subjective humans' responses to low-level, aircraft-generated sonic booms in their own homes. ${ }^{1}$ The critical research limitation of WSPR is that its human response data are, by design, not expected to determine actual public annoyance levels to sonic booms. The flight research project was conducted at Edwards Air Force Base (EAFB), which, along with the surrounding communities, is located within a supersonic corridor; therefore, it was assumed that most of the human response subjects had been widely exposed to sonic booms before the test. It was also assumed that such a test sample would provide skewed results different than that of a community that is naïve to sonic booms, which is the target audience for a full-scale sonic boom community response test. While the purpose of WSPR was not to draw any conclusions on human sonic boom tolerance, the methods developed during WSPR have helped shape the testing that will be required for any change-to-come to the current regulation of Mach number over land.

The WSPR test was a NASA collaborative effort with several industry partners, in response to a NASA Aeronautics Research Mission Directorate (ARMD) Research Opportunities in Aeronautics (ROA). The primary contractor was Wyle (El Segundo, California), responsible for overall project success. Other partners included Gulfstream Aerospace Corporation (Savannah, Georgia) - responsible for the primary microphone array; Pennsylvania State University (PSU) (University Park, Pennsylvania) - responsible for the design of community sonic boom level exposure; and Tetra Tech, Inc. (Pasadena, California) and Fidell Associates, Inc. (Woodland Hills, California) - both responsible for human response surveys. The NASA Armstrong Flight Research Center (AFRC) was responsible for logistics and flight operations, while the NASA Langley Research Center (LaRC) was the technical monitor and contract manager for WSPR. This paper focuses on the NASA role in WSPR logistics and operations, including human response subject recruitment, the operational processes involved in implementing the surveys throughout the community, instrumentation systems, flight planning, and flight operations. Sonic boom human response results, ${ }^{2}$ survey methodology conclusions, ${ }^{3}$ and community sonic boom analysis ${ }^{4}$ are presented in separate papers by the respective partners.

\section{A. Motivation}

The motivation for sonic boom human response research stems from a perceived market for commercial supersonic transportation. Shortly after the sound barrier was broken in 1947 people began envisioning the possibility of supersonic civilian transport. This idea became reality and existed for many years in the form of the Concorde; however, the Concorde was primarily operated over large oceans due to a speed restriction when flying over land. Supersonic flight over land was prohibited to avoid sonic booms on land. Sonic booms created by early supersonic military aircraft could be loud and startling, thus, restricting speed in the air regulated the noise problem on the ground.

Although there is a study that shows there is still a market for small supersonic commercial aircraft even with the current over-land restrictions, ${ }^{5}$ some will argue today that the economic model of the Concorde cannot work (that is, flying primarily over large oceans). Studies have shown that a more viable market exists for supersonic travel if that travel can be conducted over land with today's technologies (for example, higher-efficiency engines, reduced drag airframe design, et cetera.). ${ }^{6}$

For decades we have known that the shape of a vehicle has a large influence on the waveform shape, magnitude, and human perception of the sonic boom. Many studies have been conducted to examine the response of humans to various sonic boom waveforms, even having gone so far as to study what scale or metric to use to correlate the two. Past studies have shown that the perceived decibel level (PLdB) scale is an appropriate metric for typical outdoor sonic boom noise (Shepard ${ }^{7}$ and Sullivan ${ }^{8}$ ). Recently, a NASA internal study in which a small group of sonic boom research experts reacted to a range of sonic boom magnitudes supported the findings of earlier studies. ${ }^{9}$ The earlier studies suggested that sonic boom noise levels need to be on the order of 70-80 PLdB outdoors for viable community noise acceptance levels to support commercial supersonic aircraft over land. These levels, by comparison to Concorde and other supersonic military aircraft, are quiet (more than 25 PLdB less than that of the Concorde), and are often referred to as "low booms." Following an observation-of-chance of an air-launched sounding rocket, ${ }^{10}$ there have been recent demonstrations that these low boom levels can be obtained using a supersonic military jet performing a special dive maneuver, called the "Low Boom Dive."11 
As part of a NASA ARMD ROA, the Supersonics Project initiated two N+2 (two future generations) system validation efforts to design 100-passenger-scale supersonic vehicles for commercial uses that utilize low-boom shaping. ${ }^{12}$ The vehicle concepts were designed utilizing computational fluid dynamics (CFD) tools and validated in wind tunnels to match the design tools. Both studies resulted in concepts that achieved 79-81 PLdB levels, ${ }^{13,14}$ suggesting that such vehicles could be designed and built and could be acceptable in terms of sonic boom noise on the ground, both under-flight-track and off-flight-track.

A low boom demonstrator may be built at a later date to help examine the effects of and responses to shaped low booms on humans. Until then, the WSPR effort remains a first step toward developing a methodology into how such tests should be conducted so as to gather relevant community response data to low booms.

\section{B. Project Objectives}

Strategic project objectives were formed in an effort to reach the key goal of the WSPR test. The objectives consisted of investigating and validating the following: human response survey methods, data acquisition, analysis methods, the Institutional Review Board (IRB) approval process, and human response subject recruitment strategies for sonic boom human response research. The requirements and techniques used to meet these objectives are discussed in the aforementioned studies. ${ }^{2,3}$ Another project objective of WSPR was to expose a residential community with at least 100 volunteer human response subjects to low booms, which are sonic booms similar to those predicted to be produced by next-generation commercial supersonic aircraft. Ideally, the human response subjects would be uniformly spread across the community, occupying various but known types of housing structures. The predicted exposure to sonic boom levels was C-weighted day-night average sound levels (CDNL) of $42-58 \mathrm{~dB}$. This prediction is based on a 2025 projection. ${ }^{15}$ To meet this objective, these sonic booms were required to range from $0.13 \mathrm{lb} / \mathrm{ft}^{2}$ to $0.53 \mathrm{lb} / \mathrm{ft}^{2}$. Both the sonic booms on the ground and interior acoustics of residential buildings would then be measured to help validate this requirement.

Another project objective was to evaluate the recording quality and operational robustness of the Gulfstream Aerospace Corporation and PSU Sonic Boom Unattended Data Acquisition System (SBUDAS), a microphone array system that allows autonomous recording of a sonic boom over large areas. Data from the SBUDAS could be used toward validating the CDNL requirements. Such data could also be used to compare sonic boom overpressure on the ground to human response, although the statistical correlation between human response and sonic boom loudness was not an objective of this project.

\section{Flight Operations Objectives}

The WSPR flight objectives are distinguished by their relationship to aircraft flight operations. As previously discussed, project success relied heavily on the ability to produce the required sonic boom levels within the community containing the human response subjects and instrumented with the sonic boom recording instrumentation. One of the WSPR flight objectives was to produce low booms using aircraft flight assets that were already available to NASA and techniques in which NASA was already proficient. Achieving this flight objective required the precision flight of an F-18 airplane (McDonnell Douglas, now The Boeing Company, Chicago, Illinois), in the NASA-designed Low Boom Dive maneuver. In simplest terms, the Low Boom Dive is a -53-deg flight path angle inverted dive starting at Mach 0.96 and 49,000 pressure altitude (HP), with a 180-deg reverse recovery roll at approximately Mach 1.10 and 40,000 HP. In order to consistently and successfully perform the Low Boom Dive maneuver, it was required that, while supersonic, the sonic-boom-generating aircraft be capable of maintaining a constant heading within 3-deg with \pm 0.003 Mach number accuracy. This condition would help eliminate off-condition passes, resulting in an aggressive, concise flight phase. It was required that the aircraft be capable of performing at least six Low Boom Dives in one flight at previously determined pseudo-random time intervals, discussed below. Having crew in the field within the residential community was required to validate the sonic boom overpressure requirement. Field crew tasks included supporting acoustic instrumentation and providing feedback to mission control of the sonic boom levels experienced on the ground.

Because atmospheric conditions play a significant role in the propagation of sonic booms, upper-atmospheric soundings from a global positioning system (GPS) radiosonde weather balloon were required prior to each flight for mission planning purposes. Upper-atmospheric soundings were also required at aircraft takeoff time for post-analysis of sonic boom generation. Similarly, it was also a flight requirement to record meteorological data at ground level within the residential neighborhoods.

The WSPR project had a flight objective of completing its flight phase within a two-week window. In order to achieve both this flight objective and the CDNL objective, an aggressive flight schedule was required, consisting of 20-25 flights in 10 days. This objective also required having at least three F-18 aircraft (two for each mission and

4

American Institute of Aeronautics and Astronautics 
one as backup) available and prepared at all times for each flight mission throughout the demanding flight schedule. The two-aircraft flight mission is further discussed below.

\section{Background}

The ideal sonic boom community response research would occur with (1) residents going about their normal daily lives in their own homes and places of work and recreation; (2) aircraft-generated sonic booms; (3) low booms; and (4) in a community that has not been previously exposed to sonic booms. Quite a bit of research on human response to sonic booms has been done over the decades, both in laboratory settings and in the field, but none that satisfy all four of these elements. A summary of those tests that have each been done with more than 30 human response subjects inside buildings that are actually or approximately their own homes is presented in Table 1.

There are three classes of studies presented in Table 1. The first class is that of aircraft-generated and large amplitude sonic booms that affected residents in their own homes, in studies numbered 1, 3, 4, 5, 6, 8, 10, 11, and 13. These studies showed that the general public would not accept loud sonic booms, and some of the earlier ones resulted in the Federal Aviation Administration (FAA) prohibition of civil supersonic flight overland.

The second class of studies, (studies 7, 9, 12, and 15), gathered indoor data, but did not analyze data from the homes of the human response subjects. In study 7, indoor home data were gathered but not used in the analysis, as the researchers felt they needed indoor sound recordings for correlation. In Study 15, a formerly used Air Force Base home was used for testing, but none of the human response subjects lived in that home. In tests involving indoor human response subjects, studies indicate humans are more concerned about the integrity of their own home than that of a laboratory setting. For loud sonic booms, there is not a large difference in the negative attitude toward booms between renters and non-renters among those surveyed, but of the community members not involved in the survey who complained about the noise, over 90 percent are homeowners. ${ }^{25}$

The third class of studies did not use aircraft-generated sonic booms as the stimulus. Study 2 used explosive charges suspended $500 \mathrm{ft}$ above the ground near a village, detonated in pairs to simulate an N-wave sonic boom. Study 14 played sonic boom recordings in the homes of human response subjects, which included quiet and shaped sonic boom sounds. This type of test is similar to WSPR, but the numbers of human response subjects were low and the sonic booms were not aircraft-generated.

Habituation to sonic booms can also skew the results of a community noise test. The human response subjects may have become so accustomed to loud sonic booms that quiet sonic booms are hardly noticed. On the other hand, cumulative exposure to loud sonic booms may increase sensitivity to sonic booms, so that even low booms may become unacceptable. The WSPR test, study 16, satisfied three of four of the elements needed for an optimal investigation, except that the community tested has been exposed to many loud sonic booms for many years, aside from possibly some recently arrived residents. The next logical step would be to perform the same type of test in a community that has not been exposed to sonic booms before. The WSPR test was designed as a precursor to a future project that would satisfy the discussed four elements of sonic boom human response studies. 


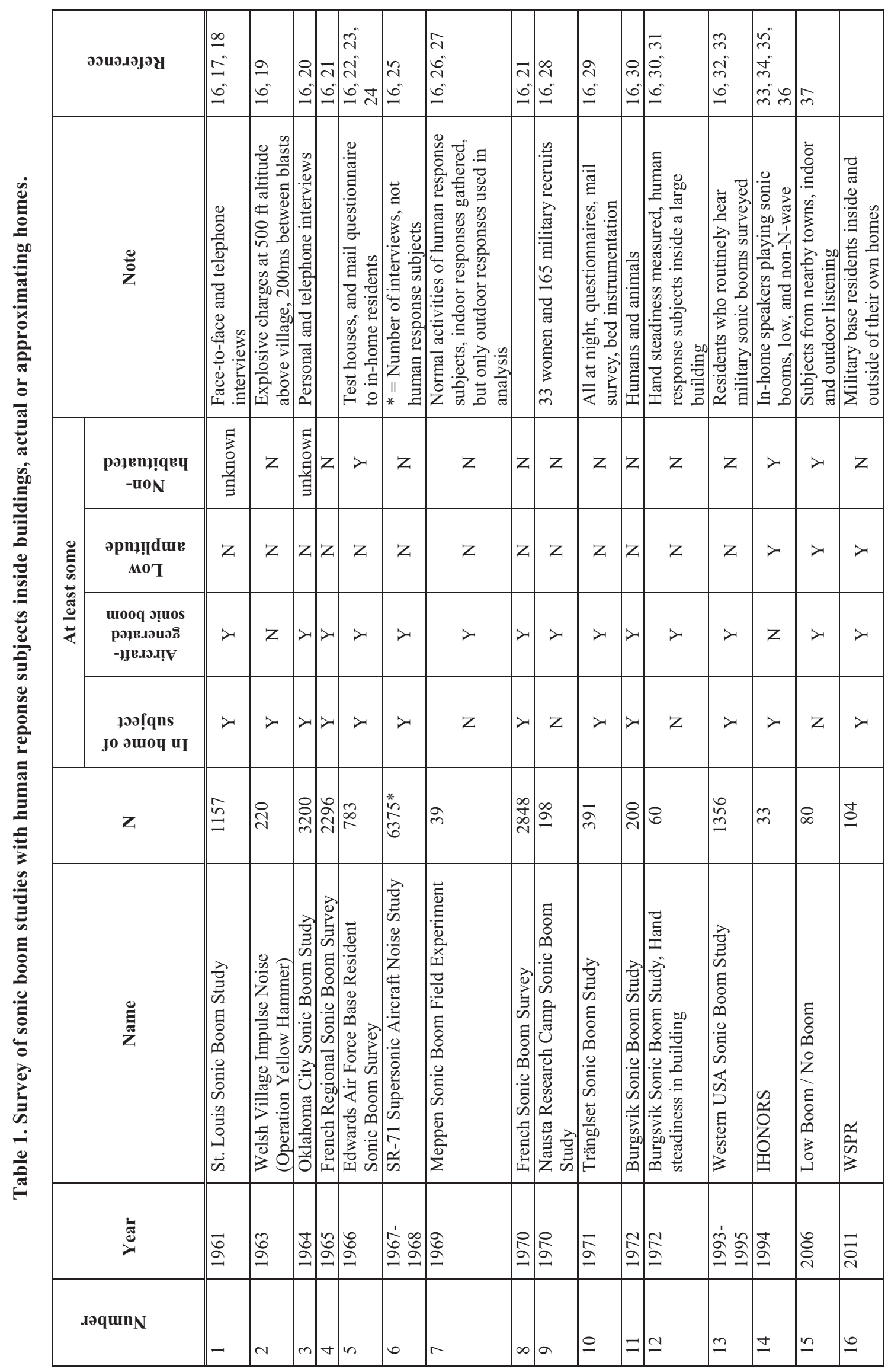




\section{Test Preparation}

Given immediately below is detail into the preparation that was required for the WSPR test, including surveys, human response subject outreach and recruitment, flight instrumentation, ground instrumentation, meteorology, and a pre-test.

\section{A. Surveys}

The human response subjects were given one of four different methods by which to complete surveys. The methods included two smartphone device methods, paper form questionnaires, and Web-based surveys. Survey methods were assigned to each participant randomly. The surveys were to be completed each time a participant heard a single event sonic boom, and a summary survey was to be completed at the end of each test day. Hodgdon ${ }^{3}$ details the methodology behind the human response questionnaires and psychoacoustics. This paper provides insight into the operational processes and logistics involved in implementing the surveys throughout the community.

For one of the two smartphone survey methods, an Apple ${ }^{\circledR}$ (Apple, Inc., Cupertino, California) iPhone ${ }^{\circledR}$ Operating System (iOS) survey application developed by Wyle was installed on participant-provided Apple ${ }^{\circledR}$ iOS devices by a WSPR member prior to the test. This installation was done "door-to-door" and included a brief tutorial. Fidell Associates, Inc. developed a Google Android ${ }^{\mathrm{TM}}$ survey application; however, this application was pre-installed on WSPR-furnished Motorola DROID 2 smartphones and distributed to human response subjects at a centralized meeting. Both smartphone methods transmitted completed surveys immediately via World Wide Web or electronic mail protocols to a data collection server.

The paper form questionnaire method required human response subjects to be sent packets with the survey materials by United States Postal Service (USPS) carrier before testing began. The packets included hard copy instructions, frequently asked questions, pre-posted return mailing envelopes, both daily summary and single event survey forms, an expanding pocket file folder to hold the materials, a pen, and contact information for technical assistance. The participants were instructed to complete the forms, put them in the envelopes, and drop them into any USPS mailbox.

Remaining participants used a World Wide Web-based survey. Participants assigned to the Web survey were asked to complete the surveys online using their own personal computer. This Web survey was designed to mirror the layout of the paper forms as closely as possible.

\section{B. Human Response Subject Outreach and Recruitment}

The National Aeronautics and Space Administration was responsible for the logistical tasks associated with human response subject recruitment. Some of these tasks included gathering information on community demographics, determining effective methods of publicizing, and facilitating the solicitation of potential volunteers.

Coordinating closely with EAFB provided the exact housing types within the community. Knowing the types of homes the human response subjects lived in was valuable, because sonic booms have different effects on different structures. All test homes were wood-frame construction with stucco siding, either duplex units or single-family detached homes. All of the two-story houses were located together in the Junior Enlisted area, as shown in Fig. 1. There were 408 duplexes (approximately 10 of which were two-story), and 388 single-family detached homes (six of which were two-story).

Projections of the occupancy and turnover rate of the community were obtained. It was found that typically the summer (June-September) was the time of the lowest occupancy rates, with occupancy ramping up to a peak in December. Summer and December were the times of highest turnover. Over any three-month period, it was estimated that there would be approximately 150 homes that were turned over. It was also noted that the Junior Enlisted parts of the community typically contain the largest number of vacant homes. This known, an estimate could be made of the number of human response subjects that were available, their locations, and the anticipated attrition, all of which affected the time of year in which the test would be conducted. This information played a considerable role in the determination that late autumn would be a suitable time for the flight phase of the WSPR test. 


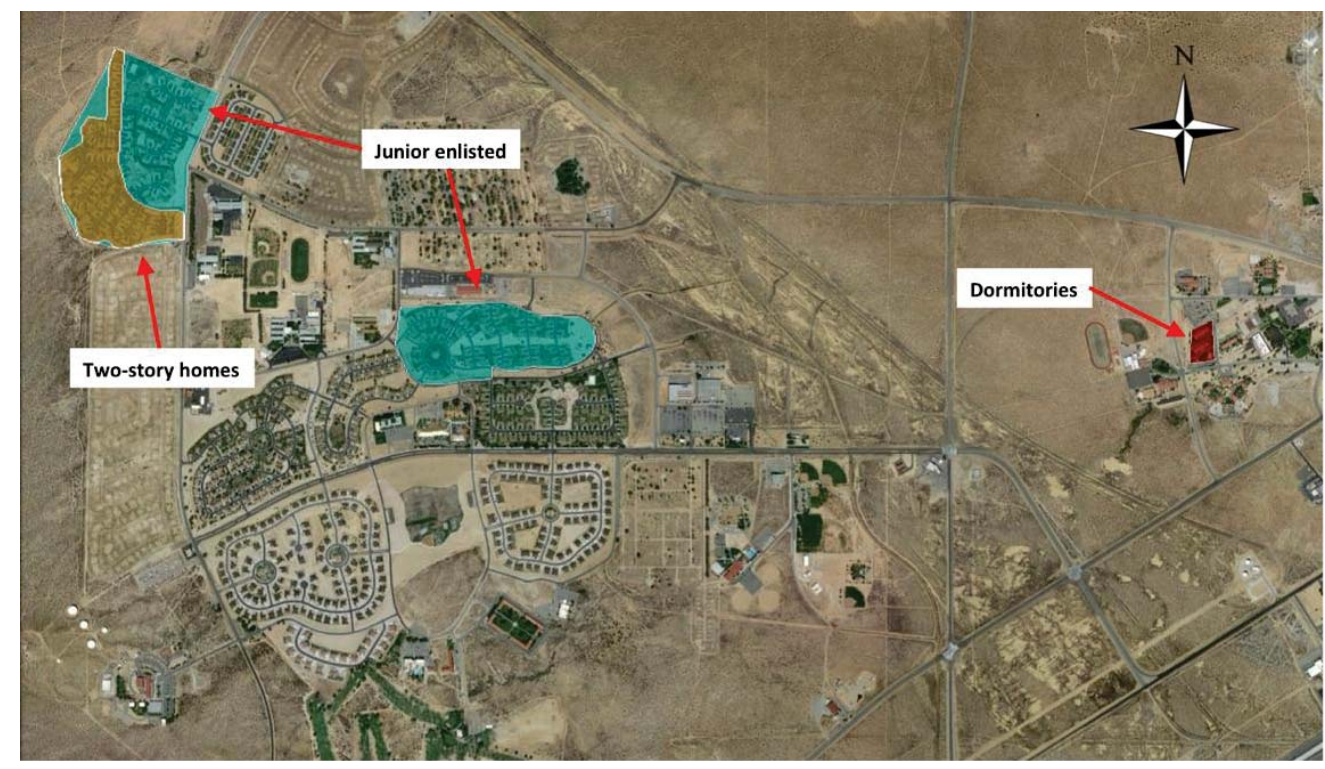

Figure 1. The Edwards Air Force Base residential community used in the WSPR test.

Successful public outreach was necessary to recruit the 100 -volunteer objective for testing. The small, intimate nature of EAFB allowed exclusive communication with the community through multiple channels, which may not have been possible in public communities. Channels of communication included electronic communications, such as electronic mail sent to all EAFB personnel, and posts on EAFB social feeds such as Facebook, Twitter, and the EAFB website. Door-to-door solicitation was not allowed on EAFB; therefore, general community-wide contact had to be made, and interested residents could decide whether to respond.

First-contact methods and solicitation to the community were conducted approximately 19 weeks before the first flight test day, through the aforementioned electronic channels as well as an article in the EAFB newspaper. The second-contact methods were through flyers posted at high-traffic areas around the community and a letter sent to all homes on EAFB. It was planned to have human subject recruitment outreach through electronic channels first, to help ensure that people would not view the hard copy letters as junk mail. The third and final contact was another article in the EAFB newspaper, this time including an offer of an incentive to all human response subject volunteers (discussed in more detail below). While there were some challenges, which are discussed below, the solicitations ultimately proved successful in that 104 human response subjects were recruited- more than the objective.

At the conclusion of testing an appreciation event was held for the participants. The event served as an opportunity to give participants an overall view of the role they had played in the test. Early results from the test were presented, and participants were able to meet some of the key WSPR personnel. The appreciation event was also an opportunity to distribute incentives and certificates of appreciation, as well as for the human response subjects to return any survey equipment or materials.

\section{Aircraft Instrumentation and Air Data Calibration}

The DFRC support aircraft fleet of F-18 airplanes were used to support the WSPR test. Two F-18 airplanes were usually required for each mission, and one as a dedicated backup, resulting in the need for a total of three aircraft available per mission. Accurate placement of the sonic boom footprint on the community requires accurate knowledge of the Mach number and altitude of the aircraft, as well as consistent repetition of the Low Boom Dive maneuver. The calibration of the aircraft production air data system in the supersonic region has errors on the order of 0.045 Mach number, which can result in up to a $1.7-\mathrm{nmi}$ error in sonic boom location. ${ }^{42}$ Each of the three F-18 aircraft used during the WSPR test required air data calibration verification. Pneumatic leaks in the pitot-static system can cause errors in indicated Mach number and altitude, thus, leak detection tests were performed to ensure the integrity of this system on each aircraft that was used.

Three aircraft (F-18A-843, F-18B-846, and F-18A-850) recently had undergone modification: the installation of a Traffic Collision Avoidance System (TCAS) antenna. The modification caused a change to the outer mold line near the air data system, which could have potentially changed the air data position error of each airplane. Air data 
calibration test flights were performed to determine what, if any, affect the TCAS antenna had on the air data position error for each airplane. The calibration flights are now discussed.

Three F-18 aircraft (F-18B-852, F-18B-846, and F-18A-850) were equipped with an Ashtech (Trimble Navigation, Ltd., Sunnyvale, California) Z-12 GPS unit. The GPS data were post-processed after each flight to add in differential corrections from the AFRC base station. The F-18A-843 was not equipped with an Ashtech Z-12 unit, so it required the use of radar tracking. The radar data provided by the Dryden Western Aeronautical Test Range (DATR) facility, whose responsibilities include telemetry tracking, radio frequency communications, and radar data, gave less accurate position information data compared to the Ashtech Z-12, but those data proved useful enough to be valid for sonic boom data analysis with higher uncertainties. Additionally, the F-18B-852 was equipped with an on-board instrumentation system referred to as Research Quick Instrumentation Data System (RQIDS). The RQIDS transmits aircraft state data (that is, attitude, airspeed, position, pitch and roll rates, et cetera) to the AFRC control room.

The NASA F-18B-852 airplane had its 1553 bus data telemetered and recorded, and also had carrier-phase differential GPS data available. Because this particular airplane is the only one of the group to have instrumented air data, and it had not undergone the TCAS modification, it was used as a reference pacesetter to compare to the other aircraft, as described in Haering. ${ }^{42}$ One air data calibration flight was flown with each of the other three aircraft to verify their air data position errors. In each case, the F-18B-852 flew in wing-to-wing formation with each of the other aircraft. Altimetry methods using carrier-phase differential GPS for inertial position and velocities combined with GPS radiosonde weather balloon atmospheric sounding were used to compute true Mach number and altitude. The non-instrumented F-18 airplane flew in formation with the F-18B-852 so both would have the same true Mach number and altitude. The pilot of the non-instrumented F-18 wrote down their air data parameters that were displayed on the heads-up display (HUD) during stabilized formation flight. These results are shown in Figs. 2, 3, and 4. Each figure compares an aircraft equipped with the TCAS antenna to the F-15B-852, which acted as the experimental baseline. The large symbols represent stable on-condition test points.

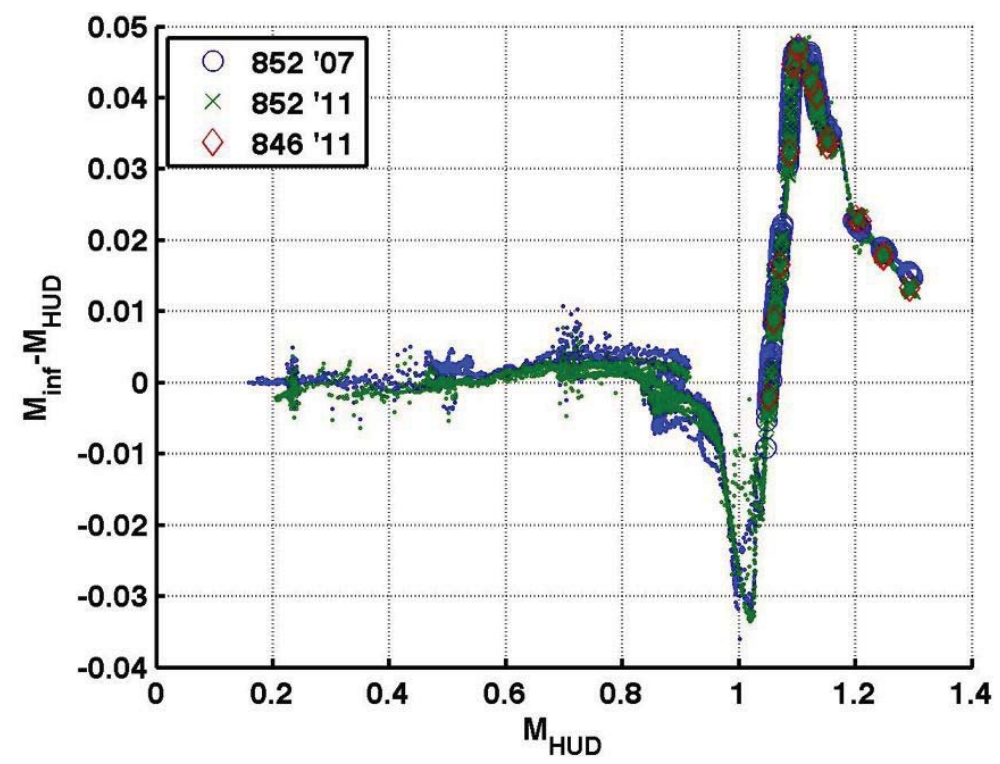

Figure 2. Mach number error for the F-18B-852 calibration flights in 2007 and on July 6, 2011; and for the F-18B-846 airplane on July 6, 2011. 


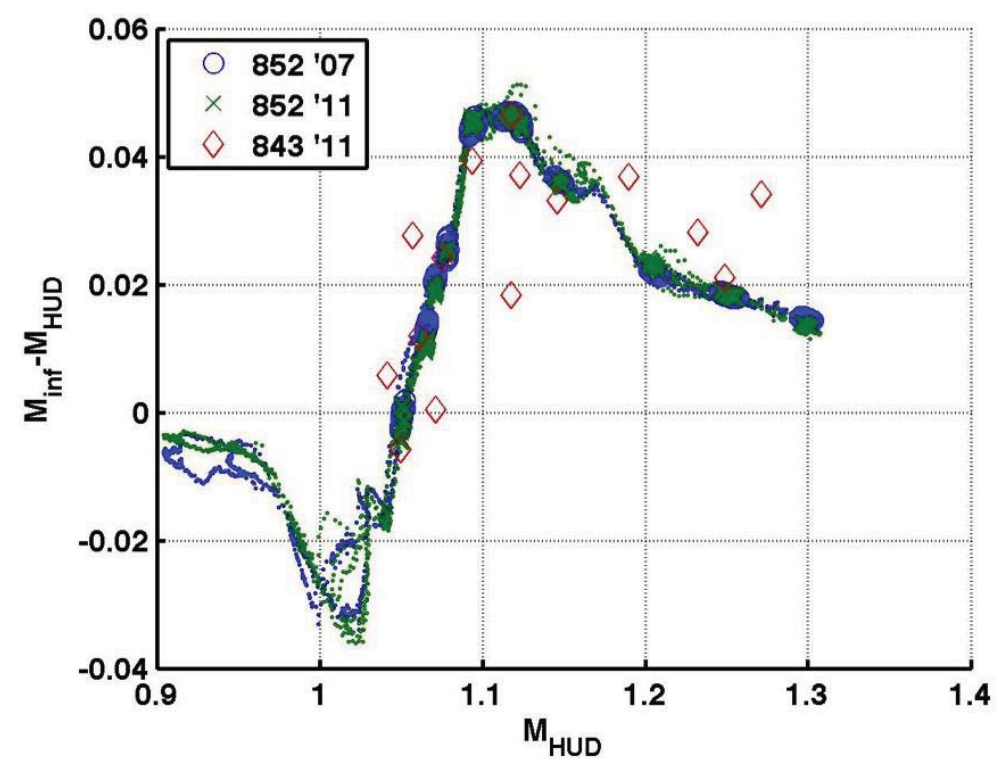

Figure 3. Mach number error for the F-18B-852 calibration flights in 2007 and on September 15, 2011; and for the F-18A-843 on September 15, 2011.

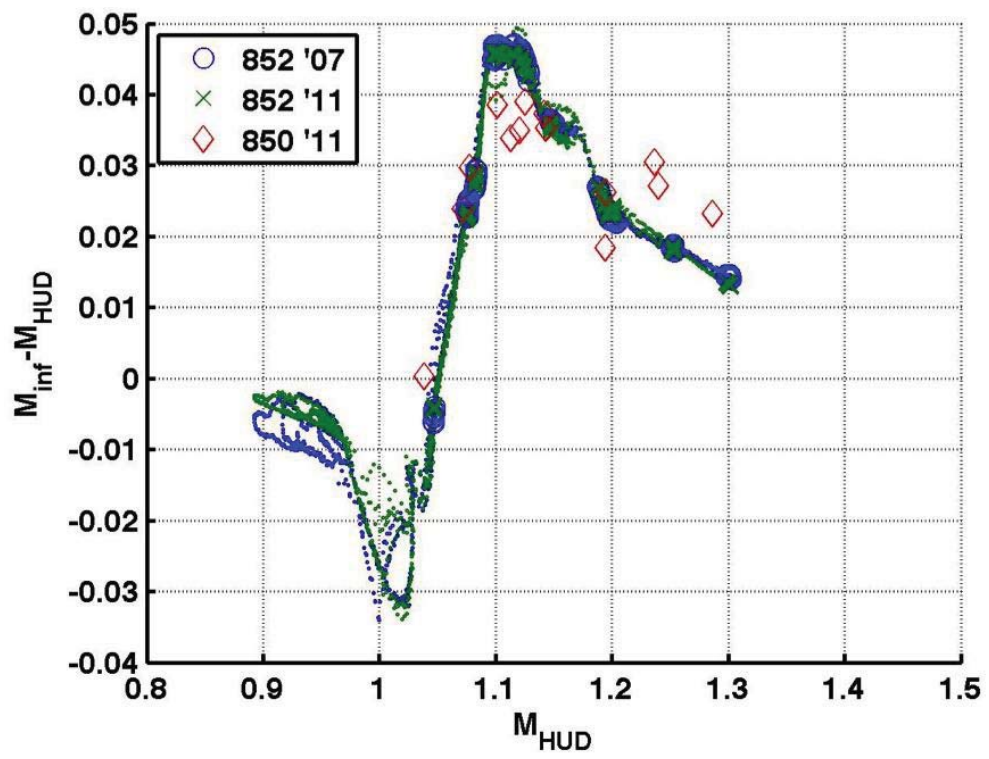

Figure 4. Mach number error for the F-18B-852 calibration flights in 2007 and on September 21, 2011; and for theF-18A-850 airplane on September 21, 2011.

The F-18A-843 data had a larger dispersion from the F-18B-852 data than the F-18B-846 and F-18A-850 data, likely due to the difference in data collection methods discussed above; however, the data showed no systematic shift with respect to the baseline, and so it was determined that the TCAS modification had no discernable effect on the supersonic Mach and altitude error of the aircraft.

\section{Ground Instrumentation}

Aside from those of the human response subjects, the most vital measurements were the acoustic recordings of the sonic booms and the atmospheric conditions. The sonic boom measurements were necessary to correlate the presence and timing of the sonic booms to the survey feedback of the human response subjects. Sonic boom propagation is a function of many factors, including atmospheric conditions. Below is an explanation of the four 
different ground (non-aircraft) instrumentation systems used during WSPR: SBUDAS; the Supersonic Notification Of OverPressure Instrumentation (SNOOPI); indoor microphones; and meteorological instrumentation.

\section{Sonic Boom Unattended Data Acquisition System}

The SBUDAS microphone array served as the primary sonic boom recording system for the WSPR test. The location of the system was within the residential and dormitory communities of EAFB. The locations were chosen to coincide with the residences of human response subjects. The array consisted of 13 SBUDAS recorders, six Wi-Fi communications repeaters, and two host stations. An SBUDAS recorder consists of a ground microphone that is solar powered with bi-directional wireless Wi-Fi communication with a host workstation, as shown in Fig. 5. Data recording of the SBUDAS system was controlled from the host stations.

The SBUDAS measured community exposure to sonic booms and was capable of capturing time-synchronous acoustic data across the entire EAFB residential community. The SBUDAS recorders were placed where human response subjects were most dense. The Gulfstream Aerospace Corporation and PSU contributed and operated the SBUDAS system. Details on its design have been published. ${ }^{39}$
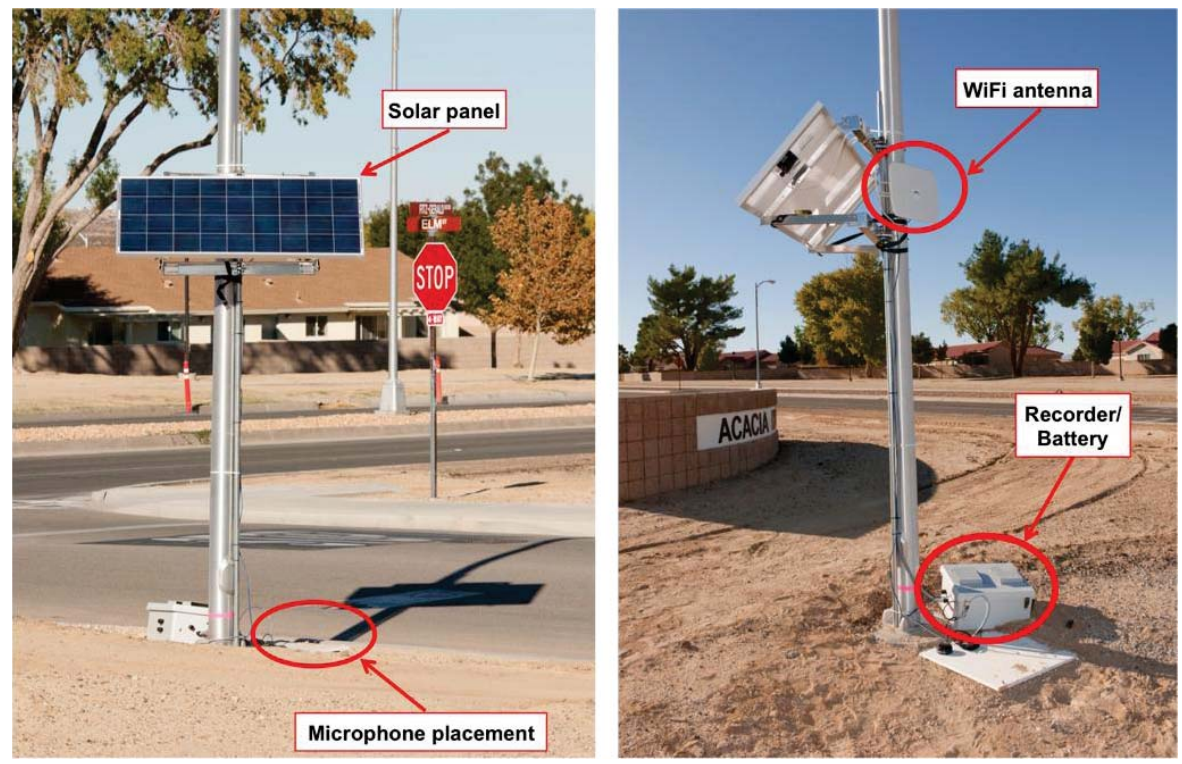

Figure 5. An SBUDAS installation.

The 13 SBUDAS recorders were deployed throughout the community at the locations illustrated in Fig. 6 . The yellow icons indicate the locations of houses of human response subjects. The red icons indicate the locations of the SBUDAS recorders. In addition to the SBUDAS recorders, there were locations for two host stations and five repeaters. The SBUDAS recorders were triggered manually at the host stations. The primary host was referred to as "Host1;" while the other was "Host2." Host1 was centrally located within the community of the human response subjects, and was the location for which the target sonic boom levels were designed. Table 2 lists the approximate geographical locations of all SBUDAS components. 


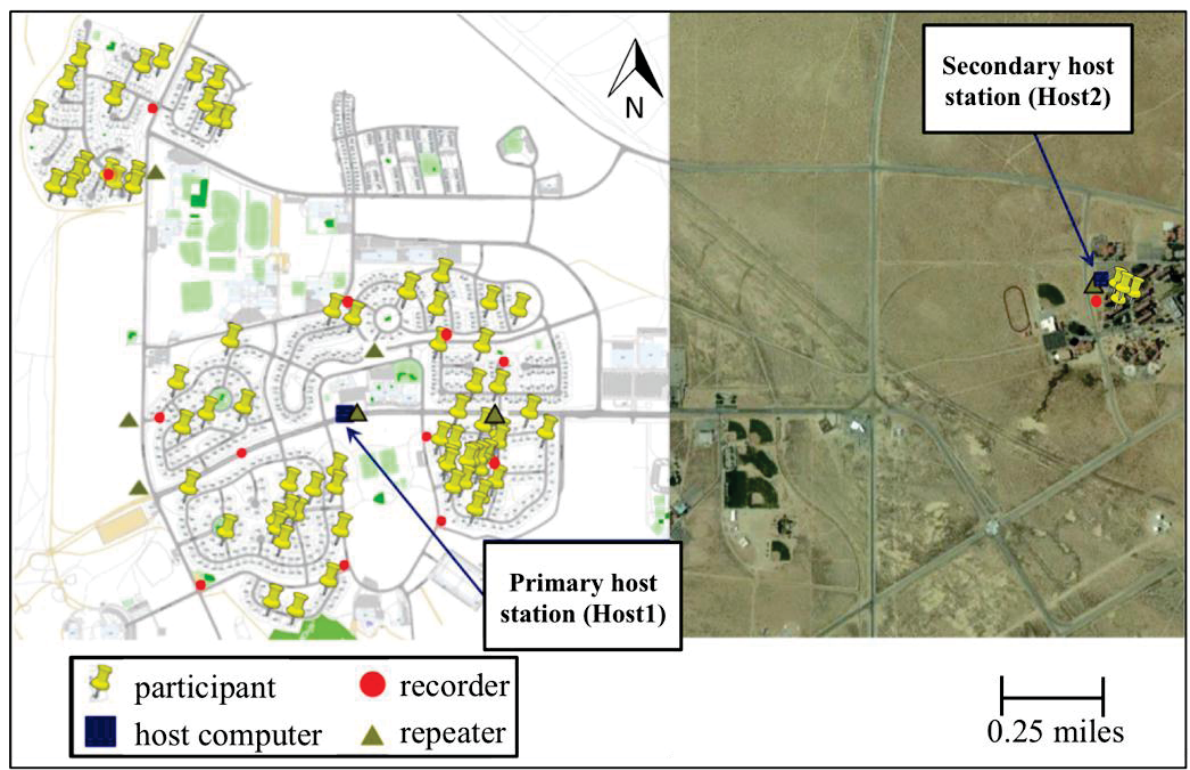

Figure 6. An aerial view of the SBUDAS array. 


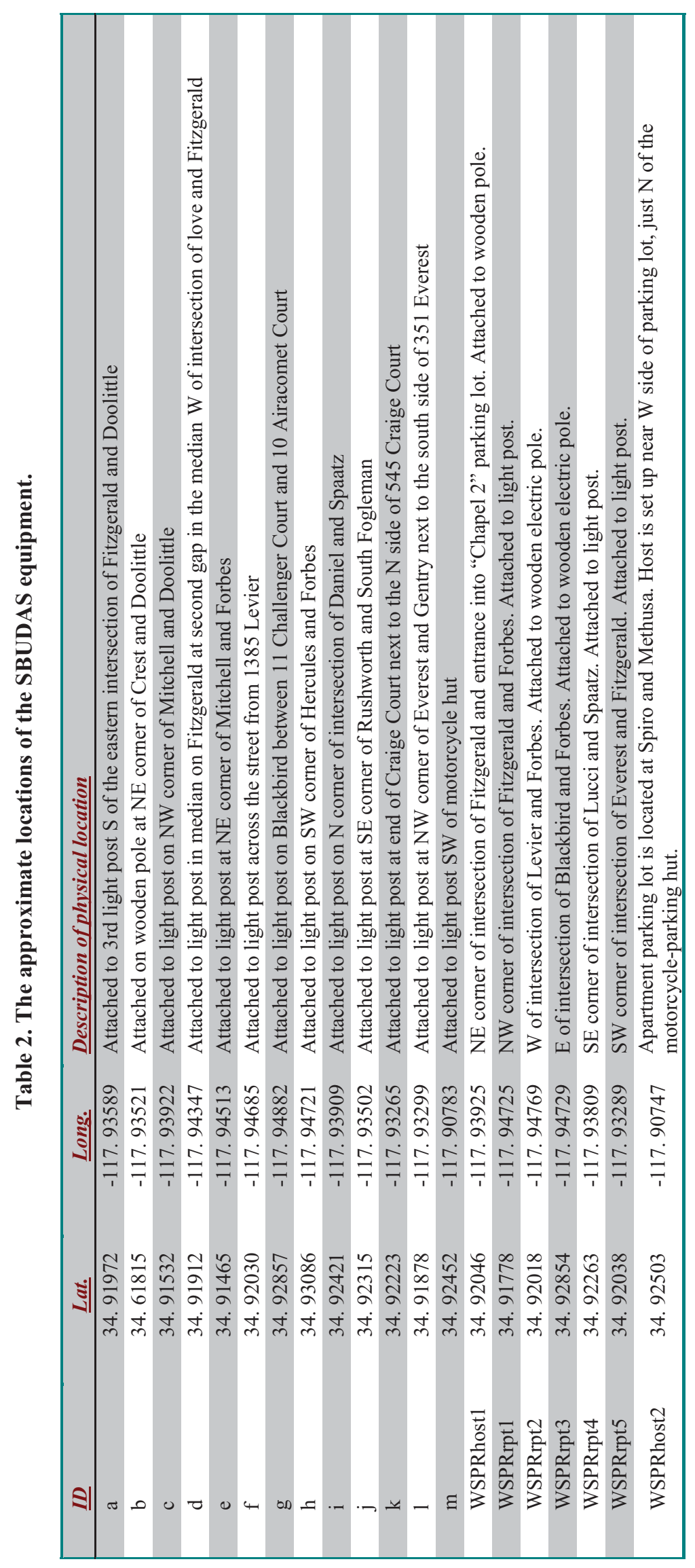

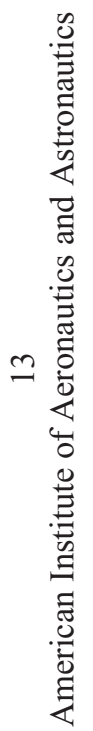




\section{Supersonic Notification Of OverPressure Instrumentation}

For the WSPR project human response subjects were asked to respond to all sonic boom events, both those generated by NASA aircraft as part of the test and by other military operations that normally occur at EAFB. The WSPR project had no advance notice of military operations, so an automatic sonic boom recording system that could operate continuously for weeks during the WSPR test was needed. There have been few automatic sonic boom recorders in the past. The Boom Event Analyzer Recorder (BEAR) of the 1970s automatically detected a sonic boom and saved the data to memory, but did not record the initial bow shock. The Portable Automated Triggering System (PATS), a 1980s vintage device, solved this problem by keeping a ring buffer of the past few seconds in memory. Once a boom was detected, the contents of the ring buffer and additional data would be recorded to capture pre-boom pressures as well as the entire boom signature. For the Shaped Sonic Boom Experiment project, NASA developed the Boom Amplitude and Shape Sensor (BASS), which combined some good features of the PATS with additional improvements.

The BASS employed the same ring-buffer technique and triggering algorithm of the PATS, but used non-volatile compact flash card memory. A GPS receiver gave accurate time-tagging and geographic location information. A filename convention was used that recorded the date and time for ease of bookkeeping. The BASS units are capable of recording up to 384 overpressure events, lasting $10 \mathrm{~s}$ each, at 8333 samples per second on a 128-MB memory card (338KB per recording), and automatically triggers when it detects a sound that exceeds the pre-determined sonic boom overpressure threshold. Two seconds of data are recorded before the boom is detected and eight seconds after. The BASS is powered by a 110-volt AC power supply.

For the WSPR project a BASS recorder was housed in a wooden doghouse to protect it from wind, rain, and dust, as shown in Fig. 7. A long extension cord from the 110-volt AC power supply was used to power the BASS; the cord was fed out from under the eaves of the doghouse. A flexible metal conduit sheathed the extension cord to prevent jackrabbits from chewing through the cord. A screen mesh was used to seal off the eaves from larger insects and animals. The differential pressure sensor for the BASS is a Honeywell (Morristown, New Jersey) SCXL004DN, which has a range of $+/-20.8 \mathrm{psf}$. The sensor was mounted to the underside of the floor of the doghouse (Fig. 8), facing down. The pressure sensor location under SNOOPI sheltered it from dew, sprinkler water, and most of the wind. The doghouse had four casters that gave it clearance from the ground, and it was placed on vinyl-wrapped plywood ground boards. A Brüel and Kjaerr (B\&K) (Denmark) hemispherical windscreen covered the sensor, and was kept in place by a screen mesh. Since all of the hardware was housed in a doghouse, the acronym SNOOPI, or Supersonic Notification Of OverPressure Instrumentation, is used to describe this device. The SNOOPI was deployed in a field near the primary host station, Host1, centrally located within the community of the human response subjects, and for which the target sonic boom levels were designed. The access hatch to the SNOOPI electronics was padlocked shut, and the SNOOPI was padlocked to a long chain around a telephone pole to reduce the chances of tampering, vandalism, or theft. The plywood boards under SNOOPI were mostly used as an acoustical groundplane, but also helped to prevent the SNOOPI from sinking in the ground. 


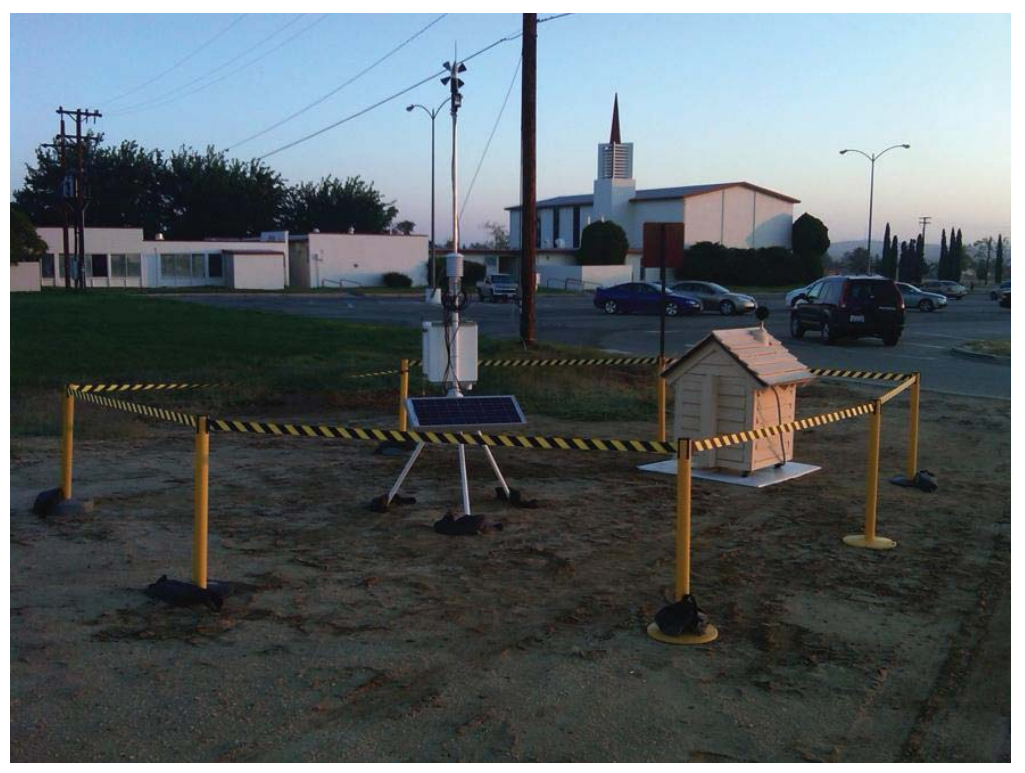

Figure 7. The SNOOPI deployed near the chapel for the WSPR test.

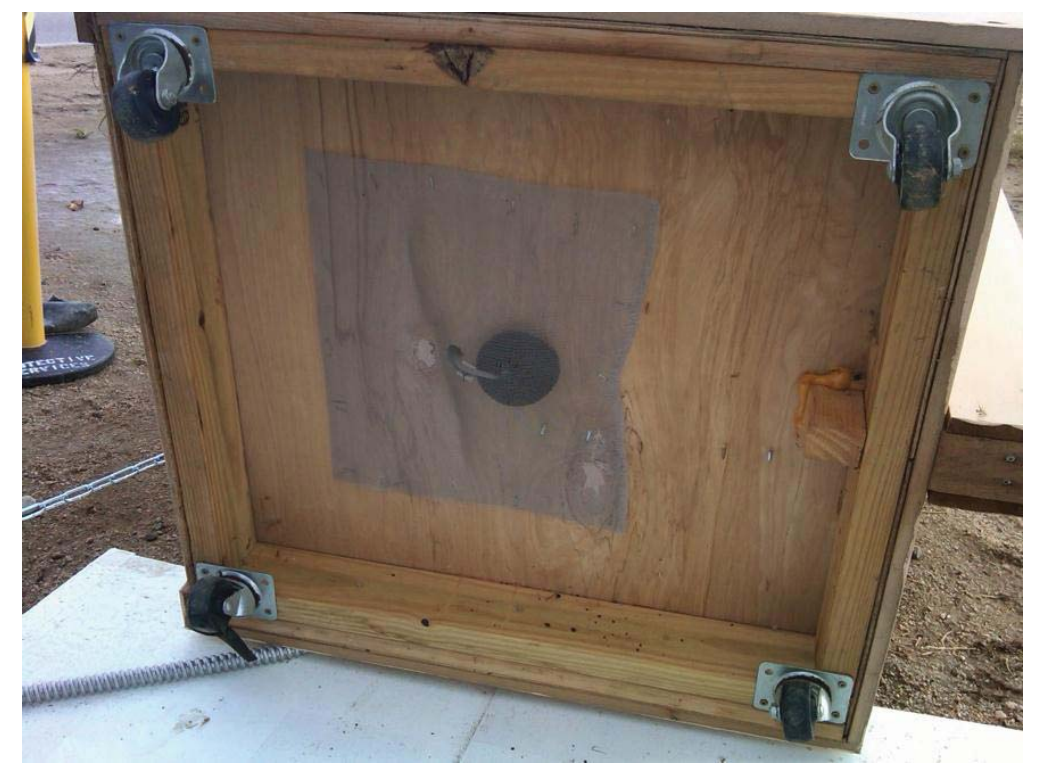

Figure 8. The underside of the SNOOPI.

One unavoidable problem with the SNOOPI (or the BASS) is that immediately after recording the sonic boom event, the unit cannot record for $12 \mathrm{~s}$ while the data are being saved to the compact flash memory card. Most of the time for sonic booms this is not a problem, unless there is a supersonic chase aircraft closely following the lead aircraft. A bigger problem occurs when wind artificially triggers the recording algorithm, filling the memory card with useless information and causing it to be temporarily unable to record. The user can set the threshold trigger level for the SNOOPI (or the BASS), setting it low (approximately $0.3 \mathrm{lb} / \mathrm{ft}^{2}$ ) on relatively calm days, or high (approximately $0.5 \mathrm{lb} / \mathrm{ft}^{2}$ ) on more windy days. Many of the booms generated by NASA for the WSPR project were as low as $0.1 \mathrm{lb} / \mathrm{ft}^{2}$; for these, a human operator pressed a manual trigger button on the SNOOPI to force a recording. As long as the button was pressed within $2 \mathrm{~s}$ of the start of the low-amplitude sonic boom, the entire signature would be recorded. The non-WSPR sonic booms that were recorded tended to be of higher amplitude, so it was assumed that most, if not all, of the non-WSPR sonic booms were recorded. 


\section{Dormitories microphones}

While the majority of the WSPR human response subjects were located in the EAFB housing area, a few were located in EAFB dormitories. In order to better understand their survey responses, two such rooms were instrumented. Wyle contributed and operated the dormitory instrumentation. One room was part of the dormitory containing survey respondents; a second, similar room was located in a separate uninhabited dormitory.

The dormitory room located near Host 2 was located on the second floor of a three-story dormitory. The room had one exterior wall, which included a large sliding window and the door. The floor was almost completely carpeted, except for approximately two square feet of tile near the back of the room. The room was equipped with a bed, desk, dresser, and chair, all of which remained in place for the test. In addition to a closet, the room had large cabinets and countertops, and shared a small bathroom with the room behind it.

In an effort to take advantage of the many sonic booms produced during this test and of the EAFB permission to instrument multiple buildings, a second uninhabited dormitory was also instrumented. This building was oriented such that the sonic booms hitting the building would be near normal incidence, and thus provide good transmission or structural sonic boom response data. This dormitory room was located on the second story of a three-story building, and was of a nearly identical layout as the previously discussed room, although this room contained no furniture.

The microphones used to instrument both dormitory rooms were B\&K 4193 infrasonic microphones, each of which was equipped with a standard 0.5 -inch preamplifier and a low-frequency adapter. This microphone setup allowed data to be gathered down to $0.1 \mathrm{~Hz}$. All three of the microphones were plugged into a B\&K NEXUSTM microphone conditioner unit; the NEXUSTM unit was connected to a PCI eXtensions for Instrumentation (PXI) chassis, housing National Instruments Corporation (Austin, Texas) 4172 cards. Along with the acoustic data, GPS time from a timecode generator was also recorded.

In the first dormitory room, near Host2, one microphone was placed on a stand in the middle of the room, another was taped to the exterior of the apartment just below the window, and one was placed on a cement pad located outside of, and approximately $25 \mathrm{ft}$ away from, the dormitory building. Additionally, four accelerometers were utilized to record the vibrational building response. One accelerometer was affixed to the tile floor, one was attached to the middle of the interior wall that did not contain the closet, one was located on the ceiling, and one was placed on the middle of the window pane. In the first instance of instrumenting a dormitory room, epoxy was used to affix one of the accelerometers to the wall; however, this proved to be difficult both in terms of keeping the instrumentation in place during the cure time and in terms of removal, because the epoxy slightly damaged the wall, which had to be repaired. The other three accelerometers were thus attached to their respective surfaces using plasticine clay.

The second dormitory room, located in the uninhabited building, was also instrumented with the same microphones, accelerometers, PXI, NEXUSTM units, and laptop computer discussed above. One microphone was placed outside on a hard, flat surface approximately $150 \mathrm{ft}$ from the building, the second was affixed to the outside of the exterior wall of the room, and the third was placed inside on a stand near a corner of the room. One accelerometer was attached to the middle of the window pane on the interior of the room, the second was affixed to an interior wall, and the third was placed on the exterior wall of the dormitory room. All of the accelerometers were attached to their respective surfaces using plasticine clay.

\section{Meteorology}

For pre-flight mission planning and post-flight sonic boom analysis, atmospheric sounding data were gathered using an airborne weather measurement package consisting of a Lockheed Martin (Bethesda, Maryland) LMS6 radiosonde unit. The unit was able to measure temperature, relative humidity, pressure, wind direction, and wind speed derived from GPS differential measurement at a ground station and the radiosonde. This package provided data from near-ground up to the flight altitudes of the aircraft. Ground-level meteorological measurements were taken using solar-powered surface weather towers that measured temperature, humidity, wind direction, wind speed, and pressure at GPS time-synced 0.5 -s increments. These surface weather towers were placed within the residential communities near Host1 and Host2.

\section{A. Pre-Test}

A "pre-test" was performed to identify possible problems with the survey questionnaire or data collection procedures. The pre-test lasted three days, was conducted approximately eight weeks before testing, and included 21 human response participants and three of the survey methods (the iOS application, the paper forms, and the Web-based response method). The human response participants were volunteer NASA AFRC employees on EAFB. 
The pre-test took place during normal business hours, and the volunteers were told to treat their office space as their home, because the questionnaires were designed to interrogate human response subjects in their own homes. Questionnaire data from the pre-test were retained and analyzed to verify that the data collection technologies executed correctly and to identify potential trouble-spots in the wording of questions or response categories before the actual test.

Of the three-day pre-testing period, sonic booms were only intentionally produced on the second day. An F-18 airplane executed six straight, level supersonic passes that would produce typical "full" N-wave sonic booms at the AFRC campus. Full sonic booms were used to assure that the pre-test volunteers would hear them, therefore increasing the questionnaire response rate. It was anticipated that sonic booms generated by normal EAFB flight operations might be generated during the other two days of the pre-testing period and indeed on each of those two days, one sonic boom was reported by most participants.

Findings and lessons learned from the pre-test are briefly described below.

\section{Test Execution}

Carrying out the WSPR project flights required many efforts, beginning with designing the sonic boom levels to be generated throughout the day within the community, to ending with data collection during flight execution. The following sections describe the sonic boom schedule and the CDNL design effort, mission planning, risks and hazards, and flight execution.

\section{A. Sound Level Design and Sonic Boom Schedule}

Three low-boom target noise levels for the design were identified and were to be generated using the Low Boom Dive maneuver: $0.13 \mathrm{lb} / \mathrm{ft}^{2}, 0.33 \mathrm{lb} / \mathrm{ft}^{2}$ and $0.53 \mathrm{lb} / \mathrm{ft}^{2}$ for the low $(\mathrm{L})$, medium $(\mathrm{M})$ and high $(\mathrm{H})$ ranges, respectively. The levels are based on the data that were obtained in a 2006 NASA AFRC field test. ${ }^{37}$ The WSPR also targeted some full (F) sonic booms levels, which were considered to be typical (approximately $1.2 \mathrm{lb} / \mathrm{ft}^{2}$ ) sonic booms generated by straight-and-level F-18 flight.

The design implemented included 21 test flights, including a human response subject training flight that was separate from the pre-test. The intent of the training flight was to generate a range of sonic booms with which to familiarize the non-naïve community with what was to be expected. It was planned to include the only full (F) WSPR sonic boom. The 21 flights occurred over a two five-day periods within a two-week window. All of these flights were conducted between sunrise and sunset. The spacing of the booms was varied based on a pseudo-random schedule meant to emulate typical air traffic. The design was optimized for equal spacing across the desired CDNL levels, and the desired CDNL levels were achieved using different sonic boom level combinations. The logic of the CDNL design is discussed in the Wyle WSPR Program Experimental Test Plan. ${ }^{1}$ Spacing of the sonic booms was constrained by the use of up to two flights per mission with unequal spacing between the booms in each flight. A "mission" is defined as a window of time during which planned sonic booms are to be generated. Two aircraft were required to fly the two flights in immediate succession to achieve the designed pseudo-random sonic boom spacing. A maximum of five sonic booms per flight allowed for unequal spacing. No two sonic booms could be closer than six minutes apart due to the time required for the airplane to be prepared for each maneuver. As such, a single-airplane flight with six or more sonic booms would result in the sonic booms being equally spaced.

The WSPR sonic boom schedule is presented below in Figs. 9 and 10. The details include the test day, the time of day for which the mission was planned, the number of booms per flight, and the level of the booms in each flight. Flight seven of WSPR is not included, because no sonic booms were generated due to an airplane mission abort. 


\begin{tabular}{|c|c|c|}
\hline \multicolumn{2}{|c|}{ WSPR Flt. 1 (Training) } \\
T1- AM & 2L, 1M, 1F & 4 \\
\hline Boom \# & $\begin{array}{c}\text { Minutes into } \\
\text { mission }\end{array}$ & $\begin{array}{c}\text { Minutes between } \\
\text { neighboring booms }\end{array}$ \\
\hline 1 & 0 & \\
\hline 2 & 8 & 8 \\
\hline 3 & 16 & 8 \\
\hline 4 & 24 & 8 \\
\hline
\end{tabular}

\begin{tabular}{|c|c|c|c|}
\hline \multirow{6}{*}{$\begin{array}{l}\text { Test day- } \\
\text { Time of day }\end{array}$} & \multicolumn{2}{|r|}{ 4L. } & 4 \\
\hline & Boom \# & $\begin{array}{c}\text { Minutes into } \\
\text { mission }\end{array}$ & $\begin{array}{c}\text { Minutes between } \\
\text { neighboring booms }\end{array}$ \\
\hline & 1 & 0 & \\
\hline & 2 & 10 & 10 \\
\hline & 3 & 24 & 14 \\
\hline & 4 & 44 & 20 \\
\hline \multirow{7}{*}{$\begin{array}{l}\text { Boom levels } \\
\text { (1 Loud, } \\
3 \text { Medium) }\end{array}$} & WSPR FIt. 3 & & \\
\hline & 12-PM & $1 L, 3 M$ & 4 \\
\hline & Boom \# & $\begin{array}{c}\text { Minutes into } \\
\text { mission }\end{array}$ & $\begin{array}{c}\text { Minutes between } \\
\text { neighboring booms }\end{array}$ \\
\hline & 1 & 0 & \\
\hline & 2 & 12 & 12 \\
\hline & 3 & 22 & 10 \\
\hline & 4 & 42 & 20 \\
\hline
\end{tabular}

\begin{tabular}{|c|c|c|}
\hline \multicolumn{3}{|l|}{ WSPR Flt. 4} \\
\hline T3-AM & $2 \mathrm{~L}, 1 \mathrm{M}, 1 \mathrm{H}$ & 4 (Flight 1) \\
\hline Boom \# & $\begin{array}{l}\text { Minutes into } \\
\text { mission }\end{array}$ & $\begin{array}{l}\text { Minutes between } \\
\text { neighboring booms }\end{array}$ \\
\hline 1 & 0 & \\
\hline 2 & 10 & 10 \\
\hline 3 & 26 & 16 \\
\hline 4 & 38 & 12 \\
\hline \multicolumn{3}{|l|}{ WSPR FIt. 5} \\
\hline T3-AM & $2 \mathrm{~L}, 1 \mathrm{M}, 1 \mathrm{H}$ & 4 (Flight 2) \\
\hline Boom \# & $\begin{array}{l}\text { Minutes into } \\
\text { mission }\end{array}$ & $\begin{array}{c}\text { Minutes between } \\
\text { neighboring booms }\end{array}$ \\
\hline 1 & 50 & \\
\hline 2 & 62 & 12 \\
\hline 3 & 72 & 10 \\
\hline 4 & 92 & 20 \\
\hline \multicolumn{3}{|l|}{ WSPR FIt. 6} \\
\hline T3-PM & $3 \mathrm{M}, 1 \mathrm{H}$ & 4 \\
\hline Boom \# & $\begin{array}{c}\text { Minutes into } \\
\text { mission }\end{array}$ & $\begin{array}{l}\text { Minutes between } \\
\text { neighboring booms }\end{array}$ \\
\hline 1 & 0 & \\
\hline 2 & 10 & 10 \\
\hline 3 & 26 & 16 \\
\hline 4 & 38 & 12 \\
\hline
\end{tabular}

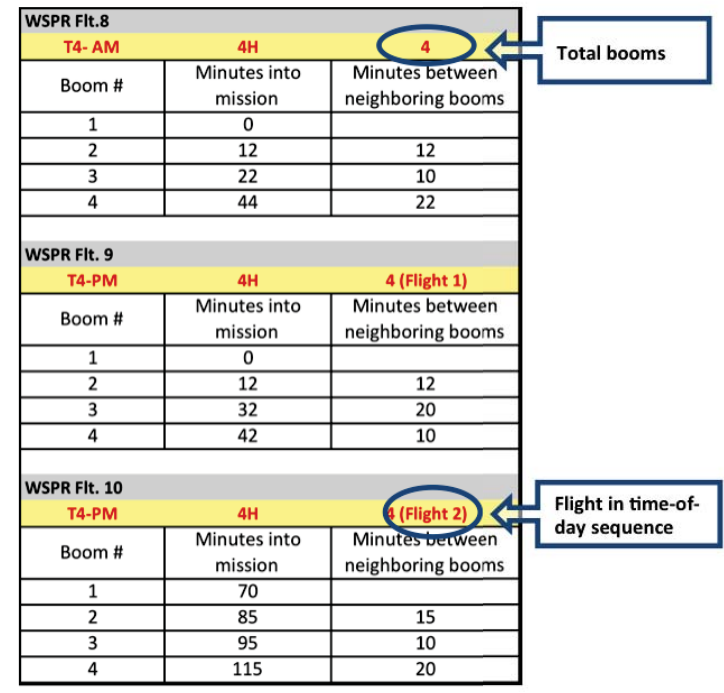

\begin{tabular}{|c|c|c|}
\hline $\begin{array}{r}\text { WSPR FIt. 11 } \\
\text { T5- PM }\end{array}$ & \multicolumn{2}{|c|}{4 M } \\
\hline Boom \# & $\begin{array}{c}\text { Minutes into } \\
\text { mission }\end{array}$ & $\begin{array}{c}\text { Minutes between } \\
\text { neighboring booms }\end{array}$ \\
\hline 1 & 0 & \\
\hline 2 & 12 & 12 \\
\hline 3 & 26 & 14 \\
\hline 4 & 44 & 18 \\
\hline
\end{tabular}

Figure 9. The WSPR sonic boom schedule, days 1-5. 


\begin{tabular}{|c|c|c|}
\hline \multicolumn{3}{|l|}{ WSPR FIt. 12} \\
\hline T6- AM & $5 \mathrm{~L}$ & 5 \\
\hline Boom \# & $\begin{array}{l}\text { Minutes into } \\
\text { mission }\end{array}$ & $\begin{array}{l}\text { Minutes between } \\
\text { neighboring booms }\end{array}$ \\
\hline 1 & 0 & \\
\hline 2 & 12 & 12 \\
\hline 3 & 22 & 10 \\
\hline 4 & 36 & 14 \\
\hline 5 & 46 & 10 \\
\hline \multicolumn{3}{|l|}{ WSPR FIt. 13} \\
\hline T6- PM & $1 \mathrm{~L}, 3 \mathrm{M}$ & 4 (Flight 1) \\
\hline Boom \# & $\begin{array}{l}\text { Minutes into } \\
\text { mission }\end{array}$ & $\begin{array}{c}\text { Minutes between } \\
\text { neighboring booms }\end{array}$ \\
\hline 1 & 0 & \\
\hline 2 & 15 & 15 \\
\hline 3 & 35 & 20 \\
\hline 4 & 45 & 10 \\
\hline \multicolumn{3}{|l|}{ WSPR FIt. 14} \\
\hline T6-PM & $4 \mathrm{M}$ & 4 (Flight 2) \\
\hline Boom \# & $\begin{array}{l}\text { Minutes into } \\
\text { mission }\end{array}$ & $\begin{array}{c}\text { Minutes between } \\
\text { neighboring booms }\end{array}$ \\
\hline 1 & 75 & \\
\hline 2 & 90 & 15 \\
\hline 3 & 100 & 10 \\
\hline 4 & 120 & 20 \\
\hline \multicolumn{3}{|l|}{ WSPR FIt. 15} \\
\hline T7-AM & $5 \mathrm{~L}$ & 5 \\
\hline Boom \# & $\begin{array}{l}\text { Minutes into } \\
\text { mission }\end{array}$ & $\begin{array}{c}\text { Minutes between } \\
\text { neighboring booms }\end{array}$ \\
\hline 1 & 0 & \\
\hline 2 & 12 & 12 \\
\hline 3 & 22 & 10 \\
\hline 4 & 34 & 12 \\
\hline 5 & 44 & 10 \\
\hline \multicolumn{3}{|l|}{ WSPR FIt. 16} \\
\hline T7-PM & $5 \mathrm{H}$ & 5 (Flight 1) \\
\hline Boom \# & $\begin{array}{l}\text { Minutes into } \\
\text { mission }\end{array}$ & $\begin{array}{c}\text { Minutes between } \\
\text { neighboring booms }\end{array}$ \\
\hline 1 & 0 & \\
\hline 2 & 8 & 8 \\
\hline 3 & 22 & 14 \\
\hline 4 & 32 & 10 \\
\hline 5 & 44 & 12 \\
\hline \multicolumn{3}{|l|}{ WSPR FIt. 17} \\
\hline T7-PM & $5 F$ & 5 (Flight 2) \\
\hline Boom \# & $\begin{array}{c}\text { Minutes into } \\
\text { mission }\end{array}$ & $\begin{array}{c}\text { Minutes between } \\
\text { neighboring booms }\end{array}$ \\
\hline 1 & 50 & \\
\hline 2 & 58 & 8 \\
\hline 3 & 78 & 20 \\
\hline 4 & 88 & 10 \\
\hline 5 & 103 & 15 \\
\hline
\end{tabular}

\begin{tabular}{|c|c|c|}
\hline \multicolumn{3}{|l|}{ WSPR FIt. 18} \\
\hline T8-AM & $5 \mathrm{~L}$ & 4 \\
\hline Boom \# & $\begin{array}{c}\text { Minutes into } \\
\text { mission }\end{array}$ & $\begin{array}{c}\text { Minutes between } \\
\text { neighboring booms }\end{array}$ \\
\hline 1 & 0 & \\
\hline 2 & 12 & 12 \\
\hline 3 & 22 & 10 \\
\hline 4 & 36 & 14 \\
\hline 5 & 48 & 12 \\
\hline \multicolumn{3}{|l|}{ WSPR FIt. 19} \\
\hline T8- PM & $1 \mathrm{~L}, 3 \mathrm{M}$ & 4 \\
\hline Boom \# & $\begin{array}{c}\text { Minutes into } \\
\text { mission }\end{array}$ & $\begin{array}{l}\text { Minutes between } \\
\text { neighboring booms }\end{array}$ \\
\hline 1 & 0 & \\
\hline 2 & 15 & 15 \\
\hline 3 & 35 & 20 \\
\hline 4 & 45 & 10 \\
\hline
\end{tabular}

\begin{tabular}{|c|c|c|}
\hline $\begin{array}{c}\text { WSPR Flt. 20 } \\
\text { T9-AM }\end{array}$ & 4L & 4 (Flight 1) \\
\hline Boom \# & $\begin{array}{c}\text { Minutes into } \\
\text { mission }\end{array}$ & $\begin{array}{c}\text { Minutes between } \\
\text { neighboring booms }\end{array}$ \\
\hline 1 & 0 & 10 \\
\hline 2 & 10 & 22 \\
\hline 3 & 32 & 16 \\
\hline 4 & 48 & \\
\hline \multicolumn{3}{|c|}{} \\
WSPR Flt. 21 & 4 (Flight 2) \\
\hline T9-AM & Minutes into \\
Boom \# & $\begin{array}{c}\text { Minutes between } \\
\text { neighboring booms }\end{array}$ \\
\hline 1 & 60 & 15 \\
\hline 2 & 75 & 20 \\
\hline 3 & 95 & 30 \\
\hline 4 & 125 & \\
\hline \multicolumn{3}{|c|}{}
\end{tabular}

\begin{tabular}{|c|c|c|}
\hline $\begin{array}{r}\text { WSPR FIt. 22 } \\
\text { T10- AM }\end{array}$ & \multicolumn{2}{c|}{5 L } \\
\hline Boom \# & $\begin{array}{c}\text { Minutes into } \\
\text { mission }\end{array}$ & $\begin{array}{c}\text { Minutes between } \\
\text { neighboring booms }\end{array}$ \\
\hline 1 & 0 & \\
\hline 2 & 8 & 8 \\
\hline 3 & 22 & 14 \\
\hline 4 & 32 & 10 \\
\hline 5 & 44 & 12 \\
\hline
\end{tabular}

Figure 10. The WSPR sonic boom schedule, days 6-10.

\section{B. Mission Planning}

Mission planning for WSPR followed the same technique as described in the appendix of Haering. ${ }^{11}$ In summary, a preflight GPS radiosonde weather balloon is launched to gather the atmospheric sounding. A trajectory of a previously flown low-boom dive or level pass is used as a template Low Boom Dive maneuver, and adjustments are made for the current atmospheric conditions. These data are then run through PCBoom, ${ }^{40}$ a sonic boom propagation prediction computer package developed by Wyle, to give a sonic boom footprint. The WSPR sonic boom schedule gives the requested overpressure for the particular flight, and the F-18 dive point is translated to place this overpressure at the center of the human response subject area, at Host1.

One new aspect added to this technique was in-the-field audible cues borrowed from the Superboom Caustic Analysis and Measurement Program (SCAMP) project. ${ }^{41}$ Once the PCBoom-derived sonic boom footprint was computed, the gradient of overpressure change as a function of distance downtrack of the waypoint was determined. If, after one of the passes the measured overpressure was higher or lower than desired, the Principle Investigator requested by way of the Mission Controller that the pilot shift his waypoint using the gradient to determine the amount of the shift. 


\section{Flight Hazards}

During the planning phase of WSPR, possible dangers to humans and mission assets were evaluated and mitigations to these hazards were identified. For all flight efforts, NASA AFRC attempts to identify any potential hazards that might result in the loss of an asset, the loss of a mission, or a compromise of human safety. While it was deemed that there were no hazards to human safety other than standard operating hazards associated with flying a supersonic aircraft, it was determined that there were significant potential hazards to mission assets, specifically field equipment. All concerns involved the potential for damage or loss of field test equipment during periods of unattended deployment.

The three possible causes of equipment damage or loss were identified to be vandalism or theft, thunderstorm activity, and precipitation, any or all of which could result in loss of data or a mission. Mitigations to the vandalism and theft hazards included securing the Wi-Fi antennas to utility poles at a height of 10-20 ft above the ground, placing SBUDAS hardware in locking National Electrical Manufacturers Association-rated (NEMA) boxes, locking the doors on the SNOOPI, securing the NEMA boxes to the base of each utility pole, briefing EAFB security personnel on the field test equipment deployment and locations, and labeling the NEMA boxes, the SNOOPI, and the surface weather towers with contact information. Mitigation of weather-related hazards was accomplished by formulating a plan to retrieve all of the microphones prior to any forecasted precipitation or thunderstorm activity, and by grounding the surface weather tower. The final mitigation was to visually check the equipment during non-flight days and to field test the equipment prior to flight operations. Throughout the test, there were no indications of any damage due to vandalism, theft, or weather.

\section{Flight Execution}

The flight execution portion of the WSPR test was comprised of two parts: 1) flight operations; and 2) control room and communications, discussed below.

\section{Flight operations}

Each flight day was preceded by a crew brief with the flight crew, Mission Controller (MC), Instrumentation Engineer, Range Control Officer (RCO), Principle Investigator, meteorologists, and Project Manager. Most briefs were performed in the afternoons prior to a test day due to early morning flights (0700 takeoff). During these crew briefs, topics that were discussed were: test objectives, aircraft configuration and maintenance status, safety-of-flight assets, mission-critical parameters, emergency procedures, mission rules, flight operating limits, control room operations, weather, flight plans, test execution, and a run-through of the flight cards. The crew briefs presented a forum for open discussion on anything that would or could affect a flight.

Most test days required one to three flights, tasking project personnel with aircraft inspections, mission flights, flight debriefs and crew briefs for the following day's flight(s). With the exception of Veterans Day weekend, the flight crew and project performed 22 consecutive flights from November 4, 2011 to November 18, 2011. The flight schedule required at least one F-18 airplane to be airborne every day, impressing a rigorous work schedule and workload on the flight crew, the field crew personnel, and the aircraft maintenance crew. Tasks by these personnel included pre- and post-flight inspections and instrumentation day-of-flight procedures, which could typically take between one and two hours to complete.

\section{Control room and communications}

For all WSPR flights, the AFRC control rooms were used to fulfill the mission-critical asset of ground-to-aircraft communication and recording of real-time flight notes. Utilizing the control room also enabled communication for the execution and ordering of test points. Required control room personnel included the MC, RCO, Communications Relay, Project Manager, and a Scribe. All WSPR flights used AFRC standard control room protocol.

The Communications Relay role was unique to the WSPR test and was a supplement to standard control room protocol. The Communications Relay filtered communications from the field crew personnel using a push-to-talk (PTT) cell phone, captured important real-time flight data, and assisted the MC with test point set-up. The Communications Relay greatly reduced the workload of the MC; assistance with test point set-up and test point execution from the Communications Relay allowed the $\mathrm{MC}$ to transmit flight test information to the Pilot-In-Command in a timely manner. Figure 11 shows a representation of the communication plan of the mission personnel. 


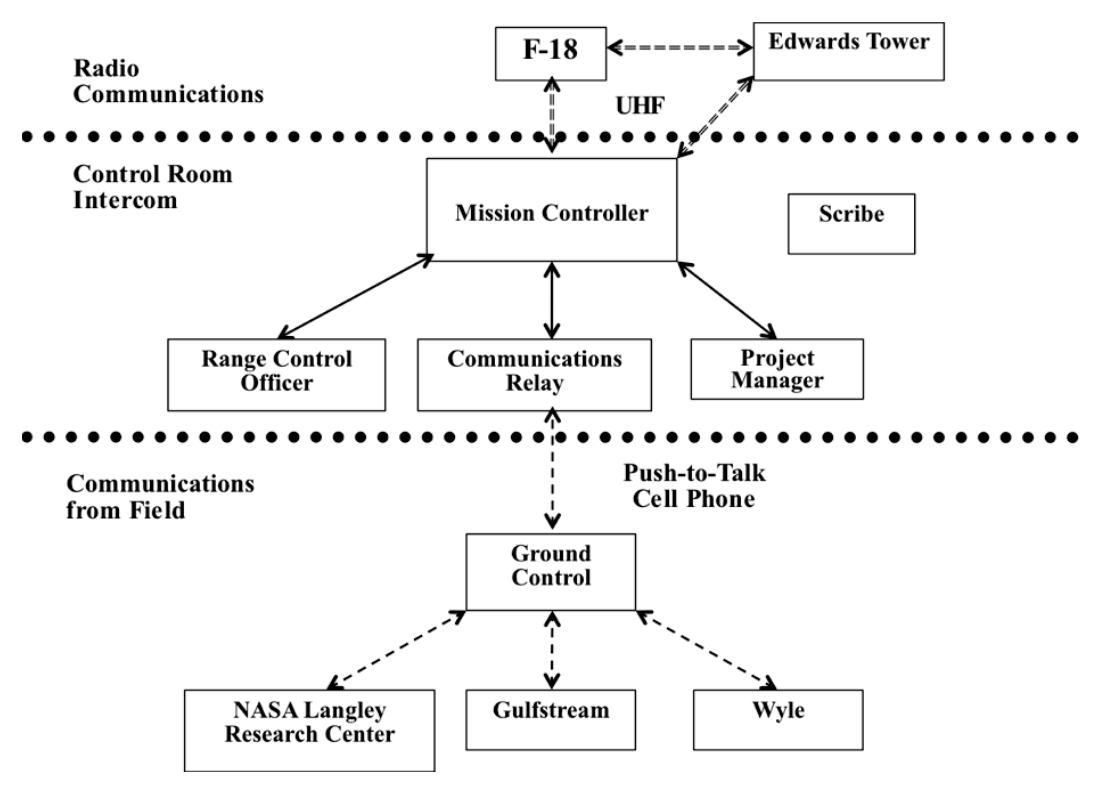

Figure 11. The WSPR communication plan.

The RCO arranged and managed control room operations and DATR assets. Prior to the beginning of every WSPR mission, the RCO verified all control room and DATR requests for that day's missions (that is, radio frequencies, telemetry, GPS, et cetera) and ensured that video equipment, tracking radar, and control room displays were properly set up and calibrated, if required. During mission execution, the RCO was available to assist with any problems that arose within the control room and relayed important flight information to the MC (for example, aircraft squawk) as needed.

During all of the WSPR flights, the Project Manager and Scribe were present. The Project Manager was WSPR's lead or manager, who ensured that the mission objectives for the test day were achieved. The Project Manager participated in the day-to-day control room operations to stay informed on the progression of the test and performed real-time calls with regard to any test or project activities that would potentially impact funding or schedule. The Scribe captured events and conversations performed throughout the test missions that were critical to sonic boom data analysis and the execution of events that occurred to obtain valuable research data.

\section{Flight Operation Results}

The primary objective of most human response tests is to gather qualitative subjective data from human response subjects as it corresponds to a quantitative stimulus of some sort. The WSPR test was different in that its focus was the tools administered to the human response subjects and the methods required to execute such a test. From a flight operations standpoint, it was important to analyze the sonic booms that were generated and to validate the fidelity of the sonic-boom-producing methods. Particular areas of interest were the overall maximum overpressures within the community, the contrast between the planned overpressure levels and the levels actually generated, the comparison between the SBUDAS and sonic boom simulation software, and the repeatability of the Low Boom Dive maneuver. Those results are discussed herein. Hodgdon ${ }^{2}$ provides results for human response data.

\section{A. Maximum Overpressure}

As discussed above, four target sonic boom overpressure levels were to be produced by aircraft during WSPR. Three low booms were intended to have overpressures of $0.13 \mathrm{lb} / \mathrm{ft}^{2}, 0.33 \mathrm{lb} / \mathrm{ft}^{2}$, and $0.53 \mathrm{lb} / \mathrm{ft}^{2}$. There were also sonic booms designated as full sonic booms, with a general target overpressure ranging between $1.2 \mathrm{and} 1.6 \mathrm{lb} / \mathrm{ft}^{2}$. There were a total of 91 sonic booms planned and attempted for the WSPR project during the flight phase, excluding the pre-test. Of the 91 attempts, 84 were targeted low booms; 89 of the 91 attempts successfully resulted in a sonic boom within the intended residential community. The two unsuccessful attempts were intended to be full sonic booms; the lack of success of those attempts was most likely due to the unanticipated last-minute planning. This topic is discussed below.

Figure 12 shows the range of sonic boom levels experienced by the human response subjects. The figure is a histogram, illustrating the frequency and distribution of the sonic boom levels within the community. These 
measurements were taken at the Host1 location using the SNOOPI. The SNOOPI recorded 88 out of 89 WSPR sonic booms. The boom that was not recorded was a planned low boom and was missed because of extremely low overpressure and a missed manual trigger, most likely due to ground communication problems (discussed below). In addition to the 89 sonic booms produced by the WSPR project, there were 14 additional advantageous sonic booms within the residential community during the two-week project flight phase. These non-WSPR sonic booms were generated by extraneous aircraft activity in the EAFB airspace.

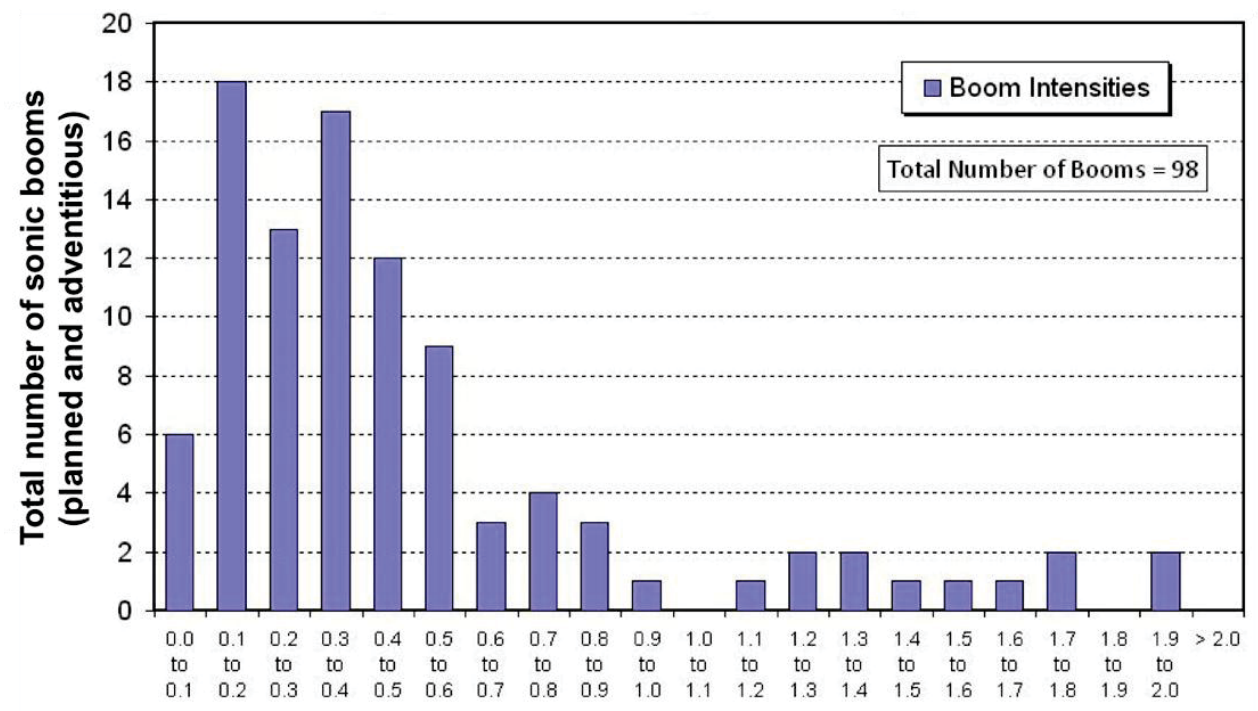

Sonic boom overpressure (psf)

Figure 12. The maximum overpressure levels as measured by the SNOOPI.

The WSPR test consisted of approximately 75 sonic booms that are considered to be low booms (less than $\left.0.60 \mathrm{lb} / \mathrm{ft}^{2}\right)$ not including the low boom missed by the SNOOPI. Low sonic booms were thus successfully planned and produced over 90 percent ( 75 out of 83 ) of its attempts.

\section{Target versus actual overpressures}

Sonic boom placement planning is a multi-dimensional problem. For a given aircraft, some of the major variables affecting the location and the intensity of a sonic boom include, but are not limited to, atmospheric conditions and aircraft maneuver accuracy. The quality of the mission planning methods and tools also has a substantial influence. While Fig. 12 helps show that the WSPR project was successful in generating low booms on the whole, Fig. 13 shows the accuracy of each individual low-boom attempt. The measurements were taken by the SNOOPI at Host1, the location for which the target overpressure were designed. Figure 13 shows the percentage of the entire dataset whose difference between the target and actual pressure measurements is below a given pressure value. For example, the difference between the target and actual pressure measurements for approximately 90 percent of the entire WSPR SNOOPI dataset was less than $0.25 \mathrm{lb} / \mathrm{ft}^{2}$. 


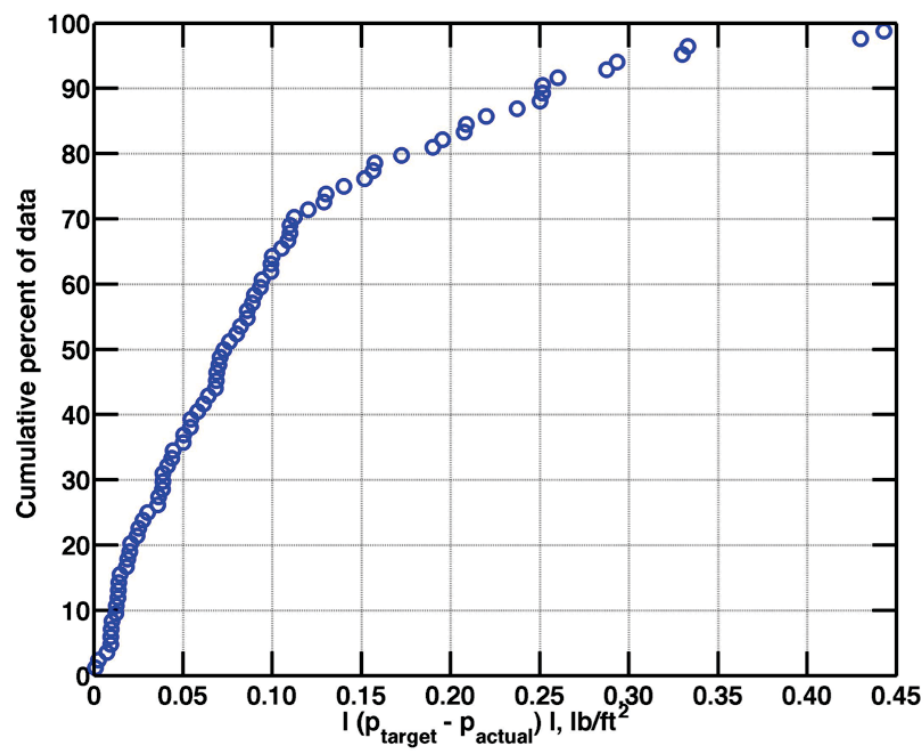

Figure 13. Cumulative percent of $\left|p_{\text {target }}-p_{\text {actual }}\right|$ at Host1.

For the 83 low-booms attempts generated during the WSPR test and recorded by the SNOOPI, 63 out of 83 (76 percent) were within $\pm 0.15 \mathrm{lb} / \mathrm{ft}^{2}$ of the planned targeted overpressures. The results illustrate the difficulty in predicting sonic boom levels of such small magnitude. It becomes increasingly difficult to predict sonic boom levels for the extremely low $0.13 \mathrm{lb} / \mathrm{ft}^{2}$ cases. This can been seen in Fig. 14, wherein the same dataset is separated into the measurements' target values, and the $\mathrm{x}$ axis is the difference between target and actual measurements as a percentage of the actual measurements. An attempt at $0.13 \mathrm{lb} / \mathrm{ft}^{2}$ resulted in an overpressure on the ground within 30 percent of the target overpressure 30 percent of the time, while attempts at 0.33 and $0.53 \mathrm{lb} / \mathrm{ft}^{2}$ resulted in overpressures within 30 percent of the target overpressure twice as often, 60 percent of the time.

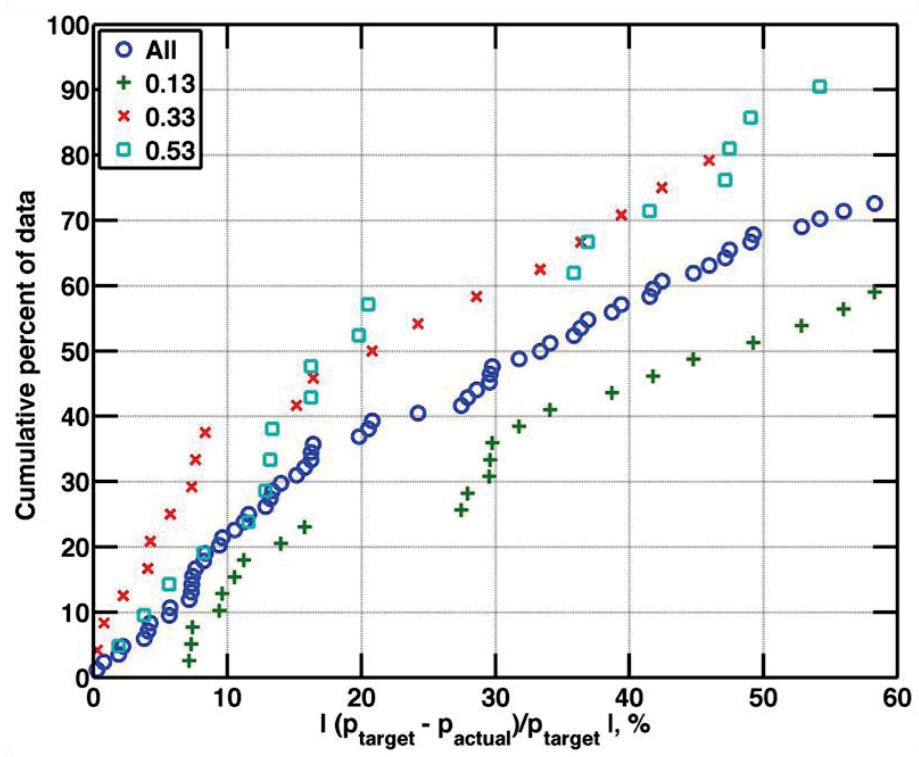

Figure 14. Cumulative percent of $\left|p_{\text {target }}-p_{\text {actual }}\right|$ broken down by target overpressure at Host1.

2. PCBoom versus SBUDAS

PCBoom, the computer program used for sonic boom mission planning, was also used for post-data analysis. Using aircraft time-speed-positional information (TSPI) in the form of radar or GPS data, or both, and 
meteorological data, PCBoom is able to simulate sonic boom propagation and provide a predicted sonic boom carpet on the ground. The program is able to predict sonic boom levels at specific locations within the simulated carpet. The same analysis method was used for the WSPR project, using the F-18 TSPI and GPS radiosonde weather balloon atmospheric sounding taken during each flight.

A comparison between the PCBoom prediction and the overpressure levels that were actually recorded for each sonic boom at every SBUDAS microphone was performed; the comparison is shown in Fig. 15. The results for each microphone were comparable, with moderate agreement between actual microphone recordings and the PCBoom program. Most of the microphones were within $\pm 0.20 \mathrm{lb} / \mathrm{ft}^{2}$ of the PCBoom predictions for approximately 40 percent of sonic booms, and only about half the dataset was within $\pm 060 \mathrm{lb} / \mathrm{ft}^{2}$ of the predictions. The apparent outlier, microphone "m," is discussed below.

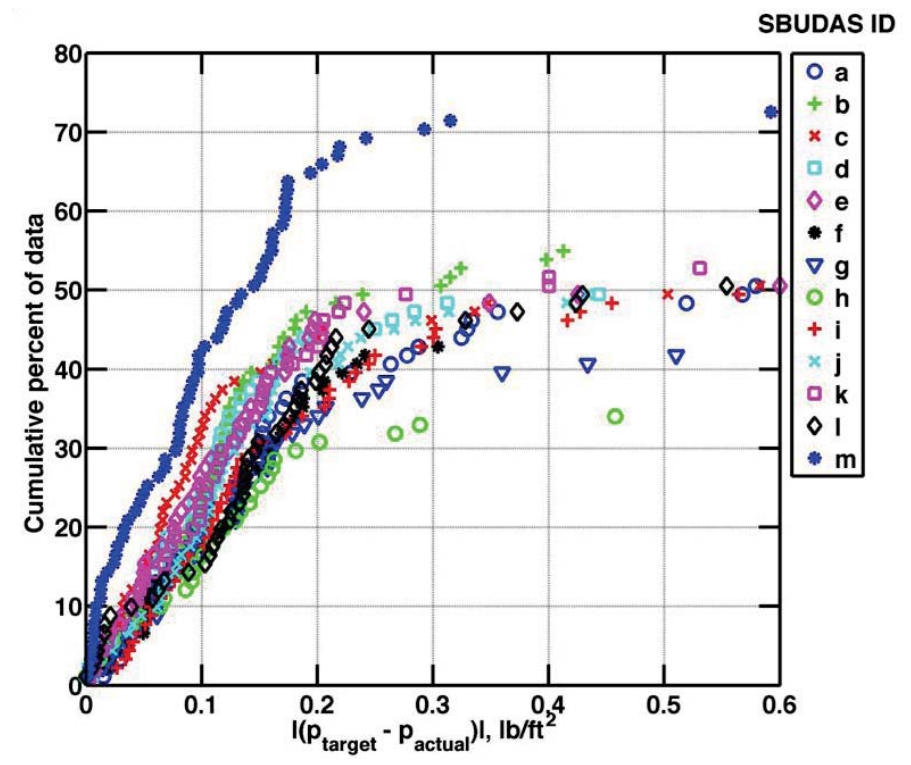

Figure 15. Comparison of $\left|p_{\text {actual }}-p_{\text {pcboom }}\right|$ at each SBUDAS microphone.

The primary reasons for this discrepancy are most likely a combination of the atmospheric turbulence effects on sonic booms, the SBUDAS microphone data analysis processes, the ability of the PCBoom program to predict very low-level sonic booms, and unsteady atmospheric conditions.

In 2007, the NASA House Variable Intensity Boom Effect on Structures (House VIBES) project performed a similar comparison between microphone data and PCBoom predictions. ${ }^{38}$ In that study, nearly 90 percent of the microphone data were within $\pm 0.20 \mathrm{lb} / \mathrm{ft}^{2}$ of the PCBoom predictions; however, House VIBES compared "idealized maximum overpressures," which is the theoretical overpressure of a sonic boom without the effect of atmospheric irregularities and aircraft influences such as atmospheric perturbations, turbulence, and variations in flight parameters. Such an approach for the WSPR test resulted in inconsistent, unreliable results. Consequently, for the WSPR test, the PCBoom predictions were compared to the true sonic boom waveforms, as recorded by the SBUDAS microphones. True sonic boom measurements can include spiking or rounding of the sonic boom signature due to atmospheric turbulence effects, which the PCBoom program does not take into consideration.

For the WSPR project, the uniform trend of the data suggests a consistent offset between microphones "a" through "l" (see Table 2) and the PCBoom predictions, also supporting a consistent yet precise inaccuracy within the microphone data. Evidence that the PCBoom program may be more accurate at predicting higher-level booms is illustrated in the distinctive trend of microphone "m. "As shown in Fig. 15, microphone "m" was placed in the easternmost position and thus was consistently within the higher-level portion of the sonic boom carpets, as the aircraft always performed the Low Boom Dive maneuver at a 260-deg true heading. Microphone " $\mathrm{m}$ " had much better agreement than the other microphones, recording within $\pm 0.20 \mathrm{lb} / \mathrm{ft}^{2}$ of the PCBoom prediction over 65 percent of the time. For House VIBES, less than half (16 out of 34$)$ of the comparisons were considered to be low sonic booms by WSPR standards. 
Furthermore, since the objective of the WSPR test did not include correlating human response data to sonic boom measurement data, resources and efforts were not concentrated on SBUDAS microphone data analysis as much as they were to other areas of the study.

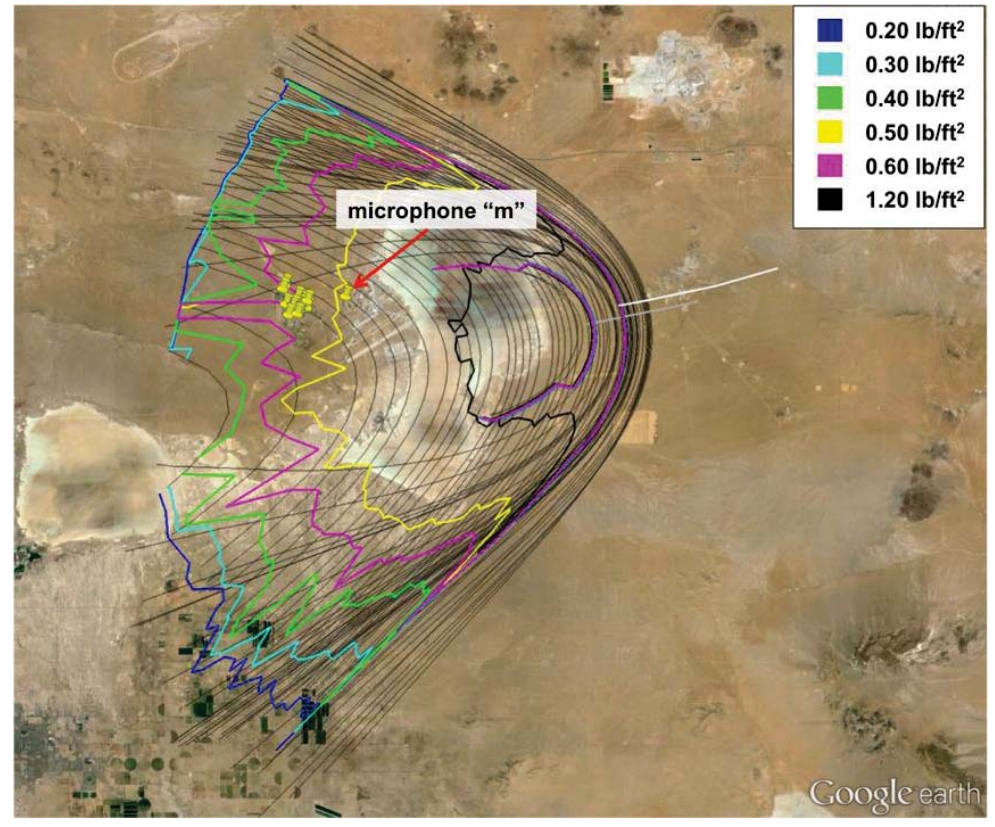

Figure 16. The PCBoom prediction, flight 05, pass 3.

\section{B. Low Boom Dive Repeatability}

All of the planning and flight operations related to the WSPR test relied upon the successful execution of the Low Boom Dive maneuver. The heading of the maneuver is based on the location and orientation of the desired sonic boom carpet. The repeatability of the maneuver was essential because of the sensitivity of sonic booms to aircraft flight conditions. Desired sonic boom levels needed to be placed with high dependability. Evaluating the high-fidelity repeatability of the Low Boom Dive maneuver is an assessment of the practicality and expectations that can be anticipated with regard to future large-scale low-boom human response tests. To analyze the repeatability of the Low Boom Dive maneuver, two flight variables were considered: dynamic pressure (to account for Mach number and altitude) and flight path angle.

Figures 17 and 18 show density plots of the repeatability of the flight path angle and dynamic pressure, respectively, for the supersonic portion of the Low Boom Dive maneuver for each WSPR sonic boom. The dark black line is the "template" Low Boom Dive maneuver, derived from historic executions of the maneuver and described to the WSPR pilots as the notional target maneuver. The template Low Boom Dive maneuver was based on NASA AFRC F-18B-852 flight 1235 pass 3, an October 16, 2010 flight for the NASA Sonic Booms on Big Structures (SonicBOBS) project. It is the same template maneuver used for mission planning. The black dotted lines in the figures are actual flight data of each Low Boom Dive maneuver executed during the WSPR test. The color contours correspond to the density of combined aircraft trajectory points, with the dark red indicating the most consistency between maneuvers. 


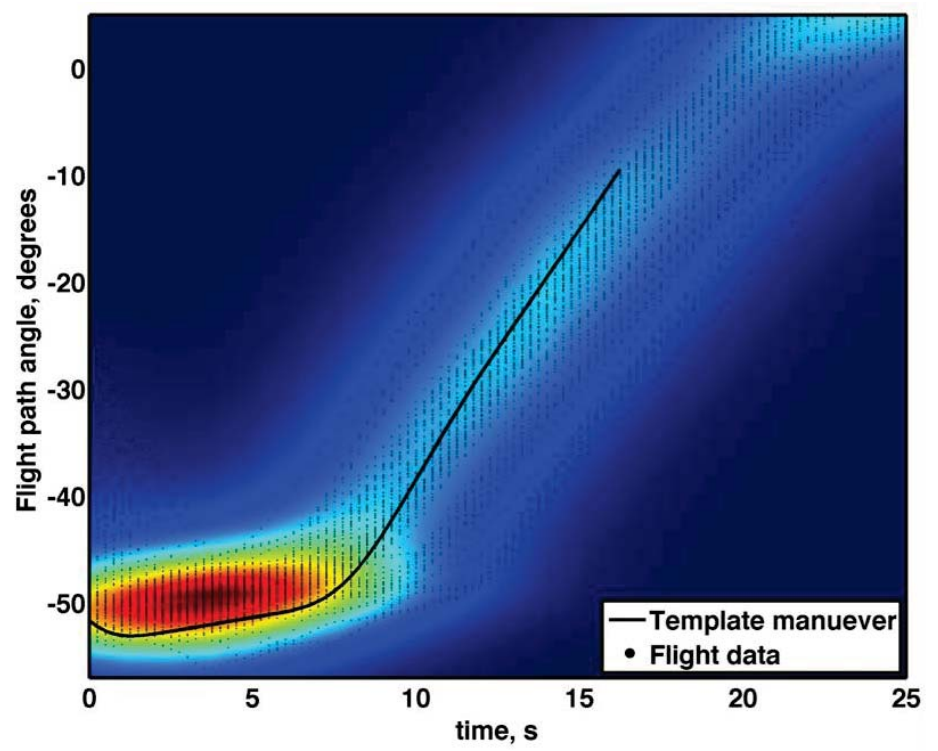

Figure 17. Low boom dives flight path angle.

Flight path angle appears to be generally consistent. While there is notable overall offset from the template maneuver, the 84 WSPR Low Boom Dives are uniformly spread with the highest density seemingly being within \pm 5 deg of the template maneuver.

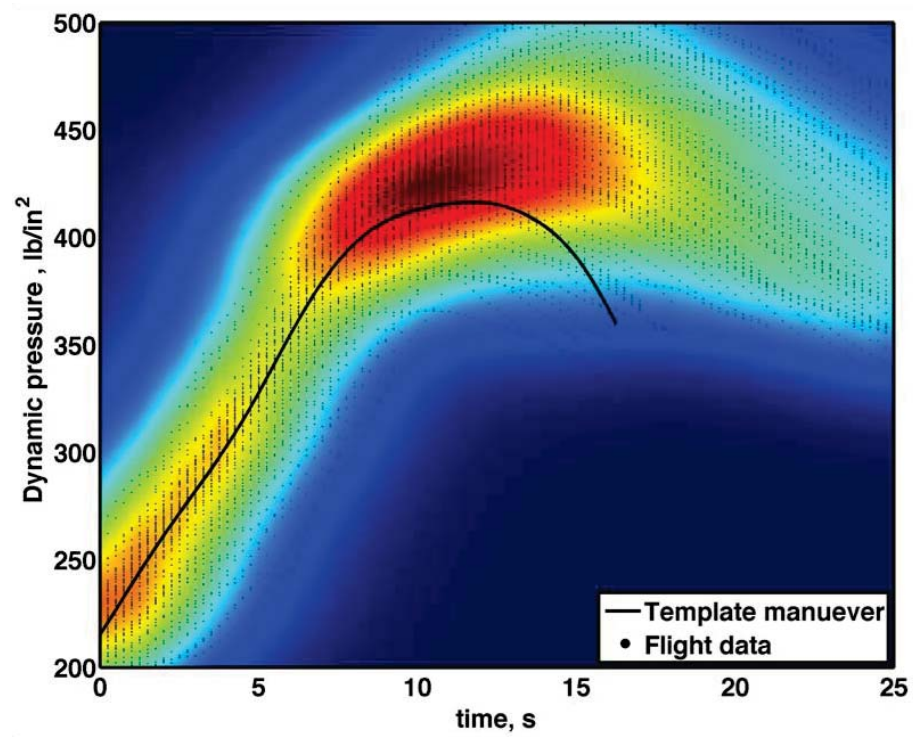

Figure 18. Low boom dives dynamic pressure.

The dynamic pressure of the WSPR test has a larger scatter than the flight path angle, particularly after the recovery reverse roll of the maneuver $(+12 \mathrm{~s})$. The lack of consistency at that point in the maneuver could contribute to the tendency for the overpressures recorded on the ground to be greater than their intended values. Fifty-nine of the 83 (71 percent) low boom maneuvers recorded by the SNOOPI resulted in overpressures greater than their target values. This condition corresponds to the majority of the WSPR maneuvers being flown at dynamic pressures considerably higher than the template maneuver, as shown in Fig. 18. The most likely causes of the lack of consistency performing the maneuver were the use of four different pilots throughout WSPR, and the need for a better-defined template maneuver. 


\section{Sonic Boom Success Rates}

Table 3 summarizes the key sonic boom success rates discussed above for WSPR.

Table 3. WSPR sonic boom success rates.

\begin{tabular}{|l|c|c|}
\hline Test description & Successful out of total & Success rate, $\%$ \\
\hline Sonic booms successfully planned and executed & 89 out of 91 & 98 \\
\hline Low booms successfully planned and executed & 75 out of 83 & 90 \\
\hline Low booms within $0.15 \mathrm{lb} / \mathrm{ft}^{2}$ of planned target value & 63 out of 83 & 76 \\
\hline Low boom attempts with overpressures higher than planned target values & 59 out of 83 & 71 \\
\hline
\end{tabular}

\section{Challenges and Lessons Learned}

The methods developed during the WSPR test have helped shape the testing that will be required for any change to the current over-land Mach number regulations. A larger, follow-on version of the WSPR effort is desired and is discussed below. The WSPR tests provided a wealth of lessons learned that might apply to future similar operations and are detailed below.

\section{A. Human Response Subject Recruitment}

While conducting the test on a small military-controlled community provided benefits, it also introduced several challenges. Some general challenges that may be specific to a military-controlled community consisted of a high turnover rate of residents and the fact that military approval of all content and occurrences pertaining to communication with residents was required.

Both the first and the second contact with community residents also presented challenges. The first recruitment contact with the community was through electronic channels, which included electronic mail messages sent exclusively to EAFB personnel. One challenge of using the EAFB electronic mail distribution list was that the list included people who did not live on EAFB. This list feature was unavoidable, and such volunteers had to be weeded out when they responded to the solicitation. The solicitation letters used for the second recruitment contact provided unanticipated challenges. Due to the sensitivity of releasing military personnel information, EAFB staff would not allow non-military parties to acquire the names and addresses of EAFB residents. Therefore, the solicitation letters had to be provided to EAFB personnel, who then mailed the letters to EAFB community residents. This process added an additional step that could not be controlled by the WSPR project and which caused delays. Additionally, EAFB required the NASA solicitation letter to be printed on official NASA letterhead, which caused an unforeseen two-week delay because NASA personnel then requested written approval for the effort to be conducted on EAFB by the base commander before the letterhead was provided. Both requests were fulfilled by the WSPR project personnel, and an additional letter, endorsed by the base commander and General, was also provided in the mailed materials, which helped to further endorse the WSPR effort.

During the early stages of recruitment and outreach planning it was thought that incentives would not be necessary to attract human response subjects because of the great working partnership and interest from the EAFB community. No raffle-like prizes could be provided for volunteers because to do so would be perceived as gambling on a military base. There was strong interest within the community after the initial outreach actions, but only about 70 of the 100 target human response subjects were recruited. The target of 100 human response subjects was out of approximately 650 households on EAFB. The determination was made that $\$ 50$ pre-paid debit cards would be offered as an incentive for all human response subjects that participated through the end of the test. Six weeks before testing, a second phase of electronic outreach and another newspaper post were distributed to promote the incentive. After the incentive was offered, a total of 104 volunteer human response subjects were easily acquired. To avoid possible legal complications, the incentives were funded through the WSPR primary contractor.

\section{B. Pre-Test}

Before the test, a pre-test allowed problems with the survey questionnaire or data collection procedures to be identified. After the pre-test and after all survey forms had been completed and accounted for, pre-test human response participants were contacted by telephone for a brief interview. Human response participants were asked about the method of data collection, ease of use, wording of questions, appropriateness of response categories, and clarity of instructions. Some of the feedback provided from the pre-test that was later used in the primary WSPR test included: increasing the number of participants assigned to Web-based as opposed to paper surveys to increase the ability to track data completeness; reviewing all data daily to facilitate participant follow-up if necessary; conducting more frequent follow-ups to ensure higher survey completion rates; and developing tools or checklists to increase 
completion rates (for example, daily task check-off lists as a reminder to complete any questionnaire material that had been neglected).

\section{Smartphones}

The AFRC had two primary roles relating to the smartphone surveying method: 1) helping facilitate the installation of the surveying software on human response subjects' Apple ${ }^{\circledR}$ iOS devices; and 2) distributing and collecting the Android phones.

The survey software for the Apple ${ }^{\circledR}$ iOS devices was installed individually, door-to-door. Installation was without many difficulties, except for the occasional need for a human response subject to update their Apple ${ }^{\circledR}$ iOS to the latest software version. One of the smartphone challenges was related to the Android phones, used by approximately 50 of the human response subjects. Because of the varying personal schedules and availability of the human response subjects, it was not possible to distribute all of the phones at one time. Seven separate meetings were required to distribute the 50 phones. Maximizing participation at these meetings would have been ideal. There was a need for the human response subjects to be trained on the phones and briefed on their role, therefore, distributing the phones individually (that is, door-to-door or by USPS mail) would have taken a considerable amount of time. A suggestion to improve the process for similar future tests is to plan and schedule the distribution and briefing well in advance in an effort to get maximum attendance. Or, the phones can be distributed individually, and the human response subjects given a tutorial video to watch.

Another challenge with the Android smartphones was collecting them at the conclusion of the test. The human response subjects were not to receive their participation incentives unless their phone was returned; however, two of the human response subjects were able to get their incentives prior to returning their phone. Unsurprisingly, this led to a nearly one-month long process of retrieving those phones. The method used to manage the return of the phones was a simple paper check-off list. For a future, larger-scale test a more sophisticated, reliable system will need to be used to manage the collection of any hardware and distribution of incentives.

\section{Ground Instrumentation}

The WSPR project provided the opportunity to learn many lessons from the challenges related to its ground instrumentation. While some of the components had been used extensively in previous sonic boom research tests, namely the SNOOPI and the meteorological equipment, this was the first time that they were used in a community response effort. For the major ground instrumentation, the SBUDAS, this was its first time being deployed for its intended purpose, which is sonic boom research.

\section{Supersonic Notification Of OverPressure Instrumentation}

The biggest challenge of using the SNOOPI was guarding against false triggers due to wind. Before the WSPR project, the SNOOPI was used on the lee side (East) of a large building. The building blocks most of the wind, and a trigger threshold of $0.30 \mathrm{lb} / \mathrm{ft}^{2}$ works well to reject wind noise but at the same time capture normal sonic booms at AFRC. For the WSPR test, the SNOOPI was placed in the middle of an open field.

During the weeks prior to the WSPR flights there were high wind days during which the trigger threshold of the SNOOPI was set to $0.30 \mathrm{lb} / \mathrm{ft}^{2}$. Two hundred twenty-six wind events were recorded, which were useful to gauge future trigger threshold values. For a trigger threshold of $0.40 \mathrm{lb} / \mathrm{ft}^{2}, 75$ percent of these wind events would have been rejected, and for a setting of $0.50 \mathrm{lb} / \mathrm{ft}^{2}, 95$ percent of the wind events would have been rejected. For later dates when the winds were predicted to be high, the threshold value of the SNOOPI was usually set to $0.50 \mathrm{lb} / \mathrm{ft}^{2}$.

The lesson learned for WSPR was thus that extensive testing prior to the tests helped to further refine the SNOOPI trigger threshold values. There were minimal false triggers due to wind during the two-week flight phase. No false triggers adversely affected the WSPR project.

\section{Sonic Boom Unattended Data Acquisition System}

Operating the SBUDAS microphone array on a military installation provided several challenges. Because the microphones were installed in the residential area of an Air Force Base, there were several layers of approval to pass through. Namely, the installation of the SBUDAS needed approval from the EAFB Space Utilization committee, EAFB Safety, and EAFB radio Frequency Management. The Space Utilization committee determines how all property and buildings on EAFB are used. This committee had to ensure that the installation of the SBUDAS would not impede normal Base operations or residential services.

Frequency Management personnel were required to ensure that the wireless communication capabilities of the instrumentation did not affect any other radio transmissions on EAFB, particularly that interference within radio frequency spectrums that affect flight operations would not be created. The instrumentation was approved, given 
some of the following restrictions: the devices could cause no interference to licensed users and the devices must accept any interference; the devices were required to operate on 802.11 Wideband Channel 6 or 11; transmitter power was limited to the offset gain of the transmit antenna; and the AFRC Radio Frequency Spectrum Management Office was required to be provided a list of all radio frequency transmitter Media Access Control (MAC) addresses and their physical locations. These restrictions are most likely specific to similar tests on or near a restricted flight range, however, comparable restrictions might apply to public communities. None of the restrictions had adverse affects on the intended SBUDAS operations from either a technical or logistical standpoint.

Edwards Air Force Base Safety personnel needed to ensure that the installation of the SBUDAS would be secure and not pose a safety risk to the community. There was particular interest in the size and placement of the solar panels that powered the units (Fig. 5). Lessons learned regarding deployment of the SBUDAS include needing to have an accurate description (size, weight, accessibility needs, et cetera) of the hardware and comprehensive documentation of all installation specifications. When initially meeting with the appropriate EAFB approval committees, these details were limited and thus the approval process was delayed. For example, the original design height of the solar panel was too low from a safety aspect. Therefore, additional wiring and re-installations were necessary to raise the panels to an acceptable level that was high enough to avoid pedestrian collisions. No dry-run installation was done, so the time required to install the SBUDAS was unknown and turned out to have been greatly underestimated. Furthermore, field crew personnel originally assumed they could work at any time of the day that might be necessary to complete the installations. Edwards Air Force Base, however, has limited work hours that extend to daylight hours only. This available work hours assumption posed potential threats to the WSPR schedule. Additional manpower mitigated these problems.

It is assumed that many these challenges would not be present for a large-scale test conducted in a public area. Most of these encounters were particulars of being on a military base. The possibility is noted, however, of similar challenges in working with local municipalities or housing associations.

\section{Dormitories microphones}

To avoid the damage that screws, nails, and epoxy would cause to the walls of the dormitory rooms, and because of the difficulty of curing epoxy in the cold environment of the dormitory rooms, most of the accelerometers were affixed using plasticine clay. This process was not without challenges, and the ceiling-mounted accelerometer routinely detached from the ceiling every few minutes. The time between booms was long enough, however, to ensure that the ceiling accelerometer could be sufficiently re-affixed to the ceiling in time for the next boom pass.

\section{Meteorology}

One of the most difficult challenges regarding the launch of GPS radiosonde weather balloons was scheduling and timing. Preflight GPS radiosonde weather balloon atmospheric sounding was input into the PCBoom program to determine the waypoints for the F-18 aircraft in order to generate a sonic boom at an exact area on the ground (Host1). Ideally, each flight would have its own GPS radiosonde weather balloon launched at takeoff to capture exact conditions for post-flight analysis; however, this was logistically challenging with the WSPR flight schedule. A normal balloon flight took approximately two hours to complete, and only one balloon was permitted to fly at a time. This limitation made it impossible for each flight to have its own GPS radiosonde weather balloon since the WSPR flight schedule often required F-18 airplane to fly twice within a two-hour window. To accommodate the post-flight analysis, a GPS radiosonde weather balloon was launched halfway between the takeoff times for each F-18 airplane, and then the same atmospheric sounding was used for both flights. The same approach was used when other missions on EAFB requested a balloon launched within two hours of the WSPR project.

During the WSPR tests, there were some instances in which a GPS radiosonde weather balloon was not launched at the desired time. This was typically due to either miscommunication or problems with the GPS radiosonde weather balloon scheduling process. The primary problem was that when WSPR flights were rescheduled, their corresponding GPS radiosonde weather balloon launch times were not adjusted accordingly. The solution was to simply confirm the launch times through multiple channels, specifically contacting the balloon launch site meteorology personnel directly, prior to the anticipated launch time.

Additionally, there were instances in which the GPS radiosonde weather balloon did not reach the desired altitude. Such occurrences are not uncommon, and were most likely due to balloon bursts or radiosonde failures. Atmospheric soundings must reach an altitude equal to the maximum flight altitude of the airplane. For the WSPR tests, the Low Boom Dive maneuver was designed to reach altitudes of at least 49,000 HP. In the instances in which the pre-flight GPS radiosonde weather balloon did not reach 50,000 HP, it was necessary to artificially extend the atmospheric sounding. To fill in the data gap, a previous atmospheric sounding was inserted from the termination point to the altitude required for pre-flight planning or post-flight analysis. This method was making the assumption 
that the weather had not changed since the previous atmospheric sounding, and introduced some unquantified error. Future flight research will have to address a standardized technique to be used in these cases. Despite these challenges, no mission planning results were compromised due to loss of weather data.

\section{E. Communications}

The ability to communicate amongst field crew personnel, as well as between the Communications Relay and the control room was crucial to mission success on many levels. The field crew personnel had to communicate with each other during daily microphone calibrations. Communication between the field crew personnel prior to the flight proved to be beneficial for troubleshooting hardware issues. Prior to the flight operation, the Communications Relay would provide the control room with a status update, and the control room would keep the field crew personnel updated on the flight status of the mission. During the mission, the control room provided calls to the Communications Relay two minutes prior to the dive, and again at $30 \mathrm{~s}$ prior to the dive. After the boom, the Communications Relay communicated whether or not the boom was heard, the overpressure of the boom, and any resulting changes to the following test point.

The aforementioned communications were facilitated by the use of a PTT network. While these radios were invaluable to mission success, the use of them was not flawless. First, the phones themselves did not always function properly. There were many instances of communications affected by strength-of-signal issues, and the phones occasionally completely stopped working. Second, there were several instances of operational error. In hindsight, the lack of signal coverage should have been discussed in advance of the test, as this is a common problem with cell phones in the EAFB area, in order to facilitate a discussion concerning phone failure mitigation; these mitigations could have proved useful in instances of operation error. Early on in the flight-test phase, the discovery was made that the operator errors stemmed mostly from over-talking and a lack of training. A brief training session on the features and use of the phones, including basic radio communication etiquette, could have prevented most of these operator errors.

While these communication problems significantly impacted three flights, since the control room was not able to notify the field crew personnel of impending sonic booms, these difficulties actually were overcome fairly easily. The Low Boom Dive maneuver created very visible and unique contrail shapes, allowing the field crew personnel to visually identify when the aircraft reached the test waypoint. These contrails, combined with communicating the sonic boom propagation time to the Communications Relay, allowed the field crew personnel to prepare for the oncoming boom and determine whether or not the boom reached the ground.

\section{F. Sound Level Design and Sonic Boom Schedule}

Since the sonic booms generated during the WSPR project were based on a pre-determined CDNL design, ${ }^{1}$ each flight's target sonic boom levels were dependent on the flights before it. Therefore, both the flight schedule and noise design were constantly changing. If the sonic boom levels and timing planned for the previous flight were not met (or if there were additional sonic booms from other EAFB flight operations), the next flight or flights were adjusted in an attempt to meet the overall design CDNL for that day. These adjustments resulted in constantly changing target flight waypoints and maneuver times. The constant adjustments also necessitated fast and robust mission planning software, and dependable communications channels to relay all changes quickly to all project personnel.

A related challenge during the WSPR project was planning to produce unanticipated full sonic booms, as opposed to low sonic booms, early in the testing. Originally it was thought that full sonic booms would not be required because infrequent extraneous sonic booms would be produced by other EAFB flight operations. As such, after the training flight, no quick turn-around process was designed for full sonic booms for the WSPR project. But due to the initial lack of non-WSPR sonic booms, full sonic booms were required, resulting in a small (two- to three-hour) delay in takeoff for mission planning. The last-minute mission planning for full sonic booms may have also contributed to two unsuccessful attempts to place full sonic booms within the residential community (the only unsuccessful attempts).

A similar challenge was due to a high volume of sonic booms generated by non-WSPR flight operations later in the testing. Being on an Air Force Base had its advantages, but one challenge was being subject to other higher-priority flight operations that were occurring in the area. It was not possible to request that there be no other supersonic flight operations on the Air Force Base. While infrequent extraneous sonic booms were anticipated, during the WSPR flight phase the community was exposed to 14 non-WSPR sonic booms. Ten of these non-WSPR sonic booms occurred on one day. Fig. 19 shows all of the sonic booms that were recorded within the EAFB community during the WSPR flight phase, as recorded by the SNOOPI. Again, non-WSPR sonic booms resulted in last-minute adjustments of the WSPR flight schedule to maintain the desired CDNL design. 


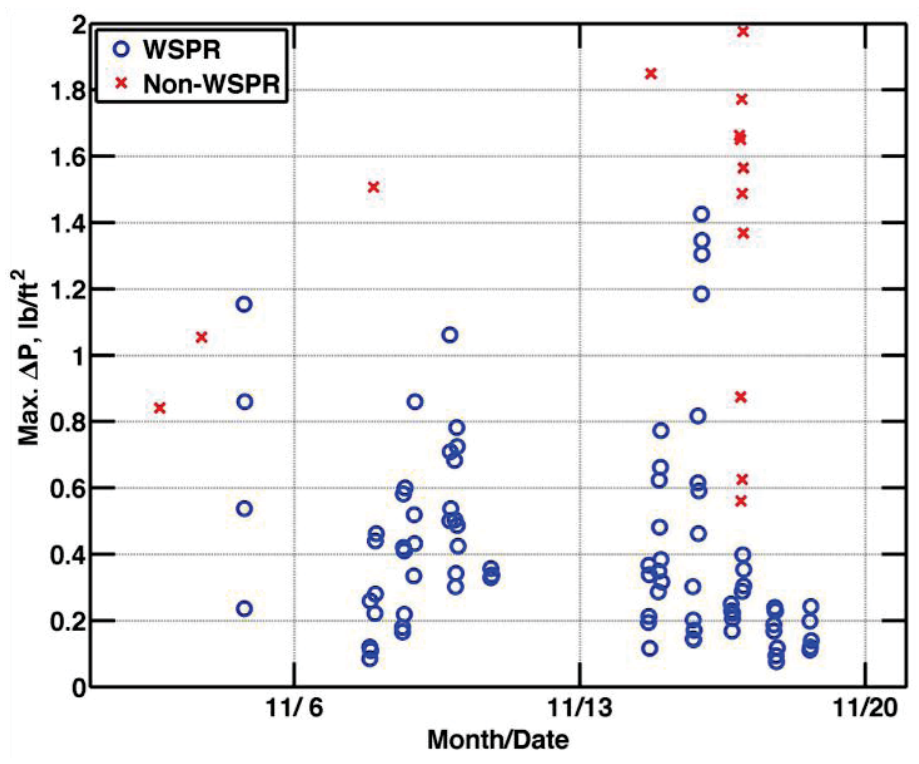

Figure 19. All sonic booms recorded within the EAFB community during the WSPR flight phase.

\section{G. Mission Planning}

For the most part, the mission planning for WSPR went according to plan, and sonic booms were generated that were well within what the experiment design called for. One difficulty occurred for a full sonic boom run that, as a result of the winds aloft for that day, needed to be run from west to east. The run placed the F-18 aircraft outside the normal military restricted area and in an area controlled by civilian air traffic controllers for the acceleration to supersonic speeds. Because of the production system pitot-static errors discussed above, when the aircraft accelerates from subsonic to supersonic, the indicated altitude (which is what the air traffic controller sees) takes dramatic climbs and descents in excess of $1000 \mathrm{ft}$. The air traffic controller cleared the F-18 airplane to accelerate at a constant altitude, which the pilot did, but the pitot-static errors made it appear to the air traffic controller that the aircraft was oscillating dramatically through the sky. This misconception caused confusion among the air traffic controllers, who are not accustomed to overseeing the flight paths of supersonic aircraft, and required clarification from WSPR mission control.

\section{H. Flight Operations}

Another challenge encountered during the WSPR flight phase was the intense flight schedule. The flight schedule was purposely built to be pseudo-random, which meant that flights could have taken off at any time throughout the test day over a two-week period. Even though the schedule was planned well in advance of the first flight day, flexibility in asset and personnel availability was paramount.

The use of PTT cell phones in both the control room and in the field presented another flight operations challenge. The additional noise of the PTT cell phones was distracting to the MC and other control room personnel during the broadcast of other radio calls made over the mission radios. The PTT cell phones also had problems receiving and providing clear information to the personnel who were conducting the test mission. A more robust communications network from the control room to the field crew personnel would have been helpful. One such network that has worked with fewer problems on similar flight projects is a land mobile radio (LMR) system.

Organization and task prioritizing would have improved the flight operations for the WSPR project. Many tasks were completed at the last minute, and multiple times there was a rush to meet WSPR milestones and deadlines. Advanced planning as well as dividing tasks among other project members would have allowed smoother flight planning and execution, improved communication with work centers (that is, flight scheduling, maintenance, range, et cetera) and alleviated stress from WSPR personnel.

\section{Future Work and Considerations}

It seems likely that sometime in the near future, international airspace will once again include supersonic civilian aircraft. Achieving that goal is a multidimensional effort, the barriers to which continue to be investigated. The 
WSPR effort was not meant to provide all of the answers, but was intended to open the door farther toward catching a glimpse of the problems that might arise in future sonic boom community response testing. The research solicitation itself, ROA NNH09ZEA001N, ${ }^{42}$ stated that this project was a pilot test for future experiments, therefore, further work is needed beyond the conclusion of the WSPR project.

\section{A. Real-time Sonic Boom Display}

A major consideration regarding community response is the prediction of sonic boom ground footprints, or a mapping of the magnitude of shockwaves on the ground due to a real trajectory through the atmosphere and airspace. A pre-flight predictor tool may be required for use by both pilots and air traffic controllers. The propagation trajectory of the shockwaves can be significantly changed by the medium through which the shockwaves travel. In other words, the impact point and strength of shockwaves can be affected significantly by weather, that is, wind, temperature gradients, et cetera. Prior to assigning a flight clearance for a low-boom supersonic aircraft, there is likely to be a need to formulate exposure predictions for the people on the ground. A set of tools is being developed and evaluated to provide these answers prior to a flight using preflight atmospheric forecasts. In fact, the current versions of these tools were used to create the WSPR flight plans and trajectories. Atmospheric forecasts, however, have known uncertainties. Pre-flight sonic boom exposure predictions based on atmospheric forecasts could result in unexpected exposures on the ground. These incorrectly predicted ground exposures could result in either a negative community response or an inefficient flight plan. A similar tool may also be needed in the cockpit, so that changes to flight plans can be evaluated during a flight, and updates to real-time weather can also be evaluated for their impact on the ground boom signature, location, and resulting exposure.

\section{B. Naïve Community Response}

Much testing has been performed on communities for higher magnitude $\mathrm{N}$-waves, and laboratory tests have been conducted examining from high magnitude $\mathrm{N}$-waves to low-magnitude shaped booms. But until the Low Boom Dive maneuver was designed, a repeatable and predictable low-magnitude shockwave community test could not be conceived. The results and lessons learned from the WSPR effort suggest that a similar test could be conducted on a community that is not accustomed to hearing sonic booms, unlike the EAFB community. Current plans call for future tests utilizing the Low Boom Dive maneuver to evaluate the response of a larger-scale community that is also unaccustomed to hearing sonic booms. This testing would help to scale up the knowledge that was gained during the WSPR testing. Also, these future tests would likely need to be conducted over multiple diverse areas that are significantly different than the area in which the EAFB community lies, such as areas of higher humidity or urban density.

\section{Low Boom Demonstrator}

The leading assumption in the Supersonics community is that the model for supersonic civil transportation will utilize shaped low-boom-generating vehicle designs. The proposed major validation of the concept is to build and demonstrate a large-scale shaped low-boom vehicle flight demonstrator. This aircraft would demonstrate tip-to-tail boom shaping in the local flow field of the aircraft and validate the capability of atmospheric boom propagation codes to predict the propagation of low booms all the way to the ground. The vehicle would also require extensive testing to verify that such a vehicle could be operated in such a way so as to result in acceptable ground boom signatures during all phases of flight and in various geographic and demographic areas. The previously mentioned larger-scale community response tests that utilized a Low Boom Dive maneuver would then be followed by a flight campaign using this flight demonstrator. This flight demonstrator would be flown to gather community response data of a low-boom shaped vehicle in all phases of flight. The data gathered during the testing of this aircraft would then be used to validate the exposure prediction tools, and would provide a body of data for regulators to evaluate toward possible changes in pertinent statutes and regulations. Such rule changes could allow the opening of an entirely new aviation market, utilizing a speed regime well above our current capabilities.

\section{Conclusions}

The WSPR project was the first community response project to use sonic booms intended to replicate the low-amplitude sonic booms that may be generated by future supersonic civil transports. A special F-18 dive maneuver was used to produce low-boom magnitudes ranging between $0.13-0.53 \mathrm{lb} / \mathrm{ft}^{2}$ onto a residential community containing 104 human response subject volunteers, over a 22 -flight 10 -day flight phase. The volunteers were successfully recruited using a wide range of outreach tactics to publicize the WSPR test, and a recruitment strategy that included community-wide correspondence and cash incentives. Easily accessible demographical data 
and several exclusive chains of communication with residents proved to be very beneficial in the human response subject recruitment process.

The WSPR test used multiple F-18 aircraft during flight operations. Each aircraft was proven to have accurate, high-fidelity air data calibrations, despite having previously undergone outer mold line modification. Such accuracy of Mach number and altitude, and innovative waypoint planning techniques, allowed the successful planning and execution of 89 out of 91 intended sonic booms, while producing low booms (below $0.60 \mathrm{lb} / \mathrm{ft}^{2}$ ) during 90 percent of the low-boom attempts. Furthermore, 76 percent of the low booms that were planned resulted in overpressures recorded on the ground that were within $0.15 \mathrm{lb} / \mathrm{ft}^{2}$ of the target value.

The Low Boom Dive maneuver showed a repeatability trend; however, the dive was generally performed at dynamic pressures higher than the target maneuver, likely contributing to overpressures recorded on the ground being greater than their target values 71 percent of the time. For future tests similar to WSPR, a different template maneuver that is more representative of how pilots flew the maneuver may need to be used for mission planning. Future test should also consider using fewer different pilots to have more consistency throughout testing.

Although data support successfully being able to plan and execute sonic booms, comparisons between sonic boom propagation software simulations and recordings throughout the community proved to have considerably less agreement. The comparisons showed agreement within $0.60 \mathrm{lb} / \mathrm{ft}^{2}$ for only half of the recordings. Such low concurrence was contributed to PCBoom being less accurate for lower magnitude sonic booms, atmospheric turbulence effects on sonic booms, and the SBUDAS microphone data analysis processes being of relatively low priority.

The WSPR study was the first known sonic boom human response study that was conducted in the homes of human response subjects, that used aircraft-generated sonic booms, and for which sonic booms were of low amplitude. The success of the WSPR project was a significant step in using human community response data as a tool to change the current global restrictions on non-military over-land supersonic travel. The WSPR study also paved the way for the next obligatory phase, which is hoped will be the process of performing a similar test on a community that is unfamiliar with sonic booms, therefore providing the first functional dataset of in-home community human responses to low-amplitude sonic booms. 


\section{References}

${ }^{1}$ Page, J., Hobbs, C., Hodgdon, K., Krecker, P., and Cowart, R., “WSPR Program Experimental Test Plan,” Wyle TN 11-03, Wyle Environmental and Energy Research \& Consulting (EERC), Arlington, VA, 2011.

${ }^{2}$ Hodgdon, K., Page, J., Gaugler, T., Phillips, D., Shumway, D., and Rosenberger, J., "Statistical Analysis of Community Response to Low Amplitude Sonic boom Noise," Proceedings of Meetings on Acoustics, Vol. 19, ICA Montreal, Canada, 2013, pp. 1-9.

${ }^{3}$ Hodgdon, K. K., and Page, J. A., "Low Amplitude Sonic Boom Noise Exposure and Social Survey Design,” Proceedings of Meetings on Acoustics, Vol. 19, ICA Montreal, Canada, 2013, pp. 1-6.

${ }^{4}$ Page, J., Hobbs, C. M., and Plotkin, K., "Waveform and Sonicboom Perception and Response (WSPR) program: Low amplitude Sonic Booms Over Small and Large Communities," Proceedings of Meetings on Acoustics, Vol. 19, ICA Montreal, Canada, 2013, pp. 1-8.

${ }^{5}$ Liebhardt, B., Luetjens, K., and Gollnick, V., "Estimation of the Market Potential for Supersonic Airliners via Analysis of the Global Premium Ticket Market," AIAA-2011-6806, 2011.

${ }^{6}$ Welge, H. R., Bonet, J., Magee, T., Chen, D., Hollowell, S., and Kutzmann, A., et al., "N+2 Supersonic Concept Development and Systems Integration," NASA/CR-2010-216842, 2010.

${ }^{7}$ Shepherd, K. P., and Sullivan, B. M., “A Loudness Calculation Procedure Applied to Shaped Sonic Booms,” NASA TP3134, 1991 .

${ }^{8}$ Sullivan, B., "Human Response to Simulated Low-Intensity Sonic Booms", Proceedings of NOISE-CON 2004, Baltimore, Maryland, 2004, pp. 1-10.

${ }^{9}$ Mabry, J. E., and Oncley, P. B., "Establishing Certification/Design Criteria for Advanced Supersonic Aircraft Utilizing Acceptance, Interference, and Annoyance Response to Simulated Sonic Booms by Persons in their Homes," FAA-RD-75-44, 1973.

${ }^{10}$ Plotkin, K. J., Haering, E. A., and Murray, J. E., "Low-Amplitude Sonic Boom From a Descending Sounding Rocket," Innovations in Nonlinear Acoustics: ISNA1 -17th International Symposium on Nonlinear Acoustics including the International Sonic Boom Forum, AIP Conference Proceedings, Vol. 838, 2006, pp. 615-618.

${ }^{11}$ Haering, E. A., Jr., Smolka, J. W., Murray, J. E., and Plotkin, K. J., "Flight Demonstration of Low Overpressure N-Wave Sonic Booms and Evanescent Waves," Innovations in Nonlinear Acoustics: ISNA1 - 17th International Symposium on Nonlinear Acoustics including the International Sonic Boom Forum, AIP Conference Proceedings, Vol. 838, 2006, pp. 647-650.

${ }^{12}$ National Aeronautics and Space Administration, "Research Opportunities in Aeronautics-2008," ROA-2008, 2008.

${ }^{13}$ Magee, T. E., Wilcox, P. A., Fuqal, S.R., Acheson, K. E., Adamson, E., and Bidwell, A. L. et al., "System-Level Experimental Validations for Supersonic Commercial Transport Aircraft Entering Service in the 2018-2020 Time Period-Phase I Final Report," NASA-CR-2013-217797, 2013.

${ }^{14}$ Morgenstern, J., Norstrud, N., Sokhey, J., Martens, S., and Alonso, J. J., “Advanced Concept Studies for Supersonic Commercial Transports Entering Service in the 2018 to 2020 Period, Phase I Final Report," NASA/CR-2013-217820, 2013.

${ }^{15}$ Rachami, J., and Page, J., "Sonic Boom Modeling of Advanced Supersonic Business Jets in NextGen," AIAA-2010-1385, 2010.

${ }^{16}$ Fields, J. M., "An Updated Catalog of 521 Social Surveys of Residents' Reactions to Environmental Noise (1943-2000)," NASA CR-2001-211257, 2001.

${ }^{17}$ Nixon, C. W., and Borsky, P. N., "Effects of Sonic Boom on People: St. Louis, Missouri, 1961-1962,” AMRL-TR-65-196, 1966.

${ }^{18}$ Nixon, C. W., and Hubbard, H. H., "Results of USAF-NASA-FAA Flight Program to Study Community Responses to

Sonic Booms in the Greater St. Louis Area,"NASA TN D-2705, 1965.

${ }^{19}$ Webb, D. R. B., and Warren, C. H. E., "An Investigation of the Effects of Bangs on the Subjective Reaction of a Community,” J. Sound Vib., Vol. 6, No. 3, 1967, pp. 375-385.

${ }^{20}$ Maglieri, D. J., and Sothcott, V. E., "Summary of Sonic Boom Rise Times Observed During FAA Community Response Studies Over a 6-Month Period in the Oklahoma City Area," NASA CR-4277, 1990.

${ }^{21}$ Bremond, Dr. J., "Reaction of the French Population to the Supersonic Bang," NASA TM-75487, 1980.

${ }^{22}$ Kryter, K. D., Johnson, P. J., and Young, J. R., "Psychological Experiments on Sonic Booms Conducted at Edwards Air

Force Base,” Final Report, Project ETU-6065, Stanford Research Institute, Menlo Park, CA, 1968.

${ }^{23}$ Farbry, J. E., Fields, J. M., Molino, J. A., and de Miranda, G. A., "Design Methodology for a Community Response Questionnaire on Sonic Boom Exposure," NASA CR-187503, 1991.

${ }^{24}$ Sutherland, L. C., and Czech, J., "Evaluation of Human Response to Structural Vibrations Induced by Sonic Booms," NASA CR-189584, 1992.

${ }^{25}$ TRACOR, Incorporated, "Public Reactions to Sonic Booms," NASA CR-1665, 1970.

${ }^{26}$ May, D. N., "The Loudness of Sonic Booms Heard Outdoors As Simple Functions of Overpressure and Rise Time," Journal of Sound and Vibration, Vol. 18, No. 1, 1971, pp. 31-43.

${ }^{27}$ May, D. N., "Sonic Boom Startle: A Field Study in Meppen, West Germany," Journal of Sound and Vibration, Vol. 24, No. 3, 1972, pp. 337-347.

${ }^{28}$ Rylander, R., Sörensen, S., Berglund, K., and Brodin, C., "Experiments on the Effect of Sonic-Boom Exposure on Humans," Journal of the Acoustical Society of America, Vol. 51, No. 2, Pt. 3,1972, pp. 790-798.

${ }^{29}$ Rylander, R., Sörensen, S., and Berglund, K., "Sonic Boom Effects on Sleep-A Field Experiment on Military and Civilian Populations," Journal of Sound and Vibration, Vol. 24, No. 1, 1972, pp. 41-50. 
${ }^{30}$ Rylander, R., Sörensen, S., Andrae, B. O., Chatelier, G., Espmark Y., and Larsson, T., et al., "Sonic Boom Exposure Effects-A Field Study on Humans and Animals," Journal of Sound and Vibration, Vol. 33, No. 4, 1974, pp. 471-486.

${ }^{31}$ Thackray, R. I., Rylander, R., and Touchstone, R. M., "Sonic Boom Startle Effects-Report of a Field Study," FAA-AM-73$11,1973$.

${ }^{32}$ Fields, J. M., "Reactions of Residents to Long-Term Sonic Boom Noise Environments," NASA CR-201704, 1997.

${ }^{33}$ Shepherd, K. P., Brown, S. A., Leatherwood, J. D., McCurdy, D. A., and Sullivan, B. M., "Human Response to Sonic Boom-Recent NASA Research," presented at the 1995 International Conference on Noise Control Engineering (INTER-NOISE 95), Newport Beach, CA, July 10-12, 1995.

${ }^{34}$ McCurdy, D. A., Brown, S. A., and Hilliard, R. D., "The Effects of Simulated Sonic Booms on People in Their Homes," AIAA-1995-0834, 1995.

${ }^{35}$ Leatherwood, J. D., Sullivan, B. M., Shepherd, K. P., McCurdy, D. A., and Brown, S. A., "Summary of Recent NASA Studies of Human Response to Sonic Booms," Journal of the Acoustical Society of America, Vol. 111, No. 1, Pt. 2, 2002, pp. 586-598.

${ }^{36}$ McCurdy, D. A., Brown, S. A., and Hilliard, R. D., "Subjective Response of People to Simulated Sonic Booms in Their Homes," Journal of the Acoustical Society of America, Vol. 116, No. 3, 2004, pp. 1573-1584.

${ }^{37}$ Sullivan, B. M., Klos, J., Buehrle, R. D., McCurdy, D. A., and Haering, E. A. Jr., "Human Response to Low-Intensity Sonic Booms Heard Indoors and Outdoors," NASA/TM-2010-216685, 2010.

${ }^{38}$ Haering, E. A., Jr., Cliatt, L. J. II, Bunce, T. J., Gabrielson, T. B., Sparrow, V. W., and Locey, L.L., "Initial Results from the Variable Intensity Sonic Boom Propagation Database,” AIAA-2008-3034, 2008.

${ }^{39}$ Cook, B., Hobbs, C. M., Page, J., and Salamone, J., "Objective Data Collection and Analysis for the Waveform and Sonic Boom Perception and Response Program (WSPR)," Proceedings of Meetings on Acoustics, Vol. 19, ICA Montreal, Canada, 2013, pp. 1-8.

${ }^{40}$ Page, J. A., Plotkin, K. J., and Wilmer, C., PCBoom Version 6 Technical Reference and User Manual, Wyle Report WR 09-20, Wylie Laboratories Inc., El Segundo, CA, 2009.

${ }^{41}$ Haering, E. A., Jr., Cliatt, L. J. II, Delaney, M. M., Jr., Plotkin, K. J., Maglieri, D. J., and Brown, J. C., "SCAMP: Rapid Focused Sonic Boom Waypoint Flight Planning Methods, Execution, and Results," AIAA-2013-0932, 2013.

${ }^{42}$ National Aeronautics and Space Administration, "Research Opportunities in Aeronautics-2009,” ROA-2009, 2009. 